\title{
Geología de recursos minerales de uso agrícola en Argentina
}

\author{
Geology of mineral resources for agricultural use in Argentina
}

\author{
Carlos Jorge Herrmann ${ }^{1, *}$
}

${ }^{1}$ Departamento de Geología, Facultad de Ciencias Exactas y Naturales, Universidad de Buenos Aires. Pabellón 2 Ciudad Universitaria. Intendente Guiraldes 2160. Ciudad de Buenos Aires. Argentina.

* Autor para correspondencia: (C.J. Herrmann) ambientemineral@yahoo.com.ar

\section{Cómo citar este artículo:}

Herrmann, C. J., 2020, Geología de recursos minerales de uso agrícola en Argentina: Boletín de la Sociedad Geológica Mexicana, 72 (3), A050520. http://dx.doi.org/10.18268/ BSGM2020v72n3a050520

\section{Manuscrito recibido: 30 de Septiembre de 2019 Manuscrito corregido: 20 de Abril de 2020} Manuscrito aceptado: 5 de Mayo de 2020

La revisión por pares es responsabilidad de la Universidad Nacional Autónoma de México.

Este es un artículo Open Access bajo la licencia CC Y-NCSA (https://creativecommons.org/licenses/by-nc-sa/4.0/)

\section{RESUMEN}

La geología en Argentina posee ambientes favorables para la generación de depósitos de minerales y rocas requeridos por el agro, tanto en su condición de aportantes de elementos nutrientes ( $\mathrm{S}, \mathrm{Ca}, \mathrm{Mg}, \mathrm{K}, \mathrm{P}, \mathrm{B}$ ) como en su función de corrector o enmienda de suelos. Los principales recursos minerales de uso agrícola son: yeso, carbonatos cálcicos y magnesianos, sales de potasio, rocas fosfóricas y, en menor medida, boratos. Los ambientes geológicos de formación de depósitos de yeso en Argentina son cinco: en la Cuenca Neuquina, se desarrollaron fundamentalmente depósitos que corresponden a las fajas litogenéticas de depósitos marinos y litorales cretácico-terciarios y de depósitos marinos jurásico-cretácico; en la región pampeana, los yacimientos pertenecen a la faja litogenética de depósitos evaporíticos cuaternarios en salares y cuencas endorreicas; en el oeste y centro-oeste argentino, corresponden a depósitos de cuenca neógenos y depósitos continentales cretácicos, mientras que en el suroeste de la Mesopotamia pertenecen a la faja litogenética de depósitos de cuencas palustre-lacustres pleistocenos.Los recursos de potasio en la Argentina pertenecen, en la Puna, a salmueras de Li - K - B en cuencas endorreicas y, en la Cuenca Neuquina, a niveles salinos con silvita en la Formación Huitrín, formando parte de una potente secuencia evaporítica.Los ambientes geológicos de formación de los depósitos de calizas y dolomías pueden agruparse en siete fajas litogenéticas: en la región central del país, en el basamento precámbrico-cámbrico (Ca y Ca-Mg) y, en menor proporción, en los depósitos de cuenca neógenos $(\mathrm{Ca})$; en la Precordillera corresponden a la plata-

\section{ABSTRACT}

Argentine geology exposes lithogenetic belts and favorable environments for the generation of deposits of minerals and rocks strongly required by agriculture, both sources of nutrient elements as corrective applications or amendments (gypsum, calcium and magnesium carbonates, potassium salts, phosphoric rocks and borates, among the main ones). Geological environments of formation of gypsum deposits in Argentina are five: in the Neuquén basin, deposits mainly corresponding to the lithogenetic belt of CretaceousTertiary marine and coastal deposits and Jurassic-Cretaceous marine deposits; in the Pampean region deposits belong to quaternary evaporitic deposits in salt flats and endorheic basins; in the west and center-west of Argentina they correspond to the girdle of neogene basin deposits and cretaceous continental deposits, while in the south-west of Mesopotamia they belong to the lithogenetic belt of pleistocene palustre-lacustrine basin deposits. Potassium resources belong to endorheic basins of the Puna with $\mathrm{Li}-K-B$ brines, and saline horizons with silvite in the Huitrin Formation forming part of the evaporitic sequence of the Neuquén basin. Geological environments for the formation of limestone and dolomite deposits in Argentina are seven: in the central region of the country deposits belong to two lithogenetic belts, the Precambrian-Cambrian basement (Ca and $(\mathrm{Ca}-\mathrm{Mg}$ ) and to a lesser extent the deposits of neogene basins (Ca); in the Precordillera they correspond to Cambrian-Ordovician carbonate platform, while in Buenos Aires to upper Precambrian - Ordovician marine deposits. In the Neuquen Basin deposits belong to the lithogenetic belt of JurassicCretaceous marine deposits. In the Neuquen 
forma carbonática cámbrico-ordovícica; en tanto que en el centro sur de la provincia de Buenos Aires pertenecen a la faja litogenética de depósitos marinos del Precámbrico superior - Ordovícico (Ca y Ca-Mg). En la Cuenca Neuquina los yacimientos pertenecen a la faja de depósitos marinos jurásico-cretácicos; en la Cuenca Neuquina y la región Central del país también se desarrollaron depósitos de rocas carbonáticas ( $\mathrm{Ca}$ y $\mathrm{Ca}-\mathrm{Mg}$ ) en la faja de depósitos marinos y litorales cretácico-terciarios; en la provincia de Entre Rios (sur de la Mesopotamia argentina) se vinculan con la faja litogenética de depósitos litorales mioceno-holocenos. Rocas fosfóricas o levemente fosfóricas se desarrollaron en los niveles marinos cretácicos y terciarios de la Patagonia; en las sedimentitas ordovícicas del noroeste argentino, principalmente el flanco oriental de la Cordillera Oriental con registro completo de edad tremadociana, y, en menor medida, en las Sierras Subandinas. También, en calizas fosfáticas y areniscas fosfáticas del Cretácico inferior de la Cuenca Neuquina.Los depósitos de boratos, utilizados en la agricultura en mucho menor proporción que los anteriormente citados por tratarse el boro de un micronutriente, se ubican en la Puna, y corresponden a dos fajas litogenéticas: las facies evaporíticas de depósitos sinorogénicos terciarios y los depósitos de salares cuaternarios, ambas vinculadas con volcanismo.

Palabras clave: yeso, carbonatos, potasio, fósforo, suelo, producción agrícola.
Basin and the Central region, deposits of carbonate rocks (Ca and $\mathrm{Ca}-\mathrm{Mg}$ ) were also developed in the belt of cretaceous-tertiary marine and coastal deposits. In the province of Entre Rios (southern Mesopotamia, Argentina), they are linked to the lithogenetic belt of Miocene-Holocene coastal deposits. Phosphoric or slightly phosphoric rocks developed at the cretaceous and tertiary marine levels in Patagonia; in the Ordovician sediments of northwestern Argentina, mainly the eastern flank of the Eastern Cordillera with full record of Tremadocian age, and to a lesser extent in the Sub-Andean Sierras; and in phosphate limestones and phosphate sandstones of the lower Cretaceous of the Neuquen Basin.Borate deposits are located in the Puna and correspond to evaporitic facies of tertiary synogenic deposits and quaternary salt deposits.

Keyzords: gypsum, carbonates, potassium, phosphorus, soil, agriculture production.

\section{Introducción}

El uso agrícola es una aplicación particular de escasas rocas y minerales industriales, tales como yeso, calizas y dolomías, silvita y otras sales de potasio, rocas fosfóricas y boratos, valiosas por ser su destino final la provisión de alimentos a las poblaciones locales y mundial (Manning, 2018). $\mathrm{Su}$ disponibilidad cobra mayor importancia relativa en un país agroexportador como Argentina, donde la disminución del contenido de nutrientes de su suelo agrícola está alcanzando valores críticos y comienza a condicionar la productividad y sustentabilidad de la actividad; el fósforo extractable está disminuyendo a razón de 1 a 2 ppm/año; el contenido de calcio ha disminuido alrededor de un $50 \%$ y se registra una acidificación creciente de los suelos, hasta de una unidad de $\mathrm{pH}$ en algunos sitios (Cruzate y Casas, 2014).
Por otra parte, el crecimiento continuo de la superficie sembrada y del volumen de granos cosechados (más de 30 millones de hectáreas y 130 millones de toneladas respectivamente, en 2019), que convierte a esta actividad en la más importante de Argentina en términos económicos, impacta en las elevadas cantidades de elementos minerales extraídos (exportados en el grano), que no alcanzan a cubrirse con la reposición de fertilizantes, redundando en balances de nutrientes deficitarios desde hace muchos años (Sainz Rozas et al., 2013).

El yeso ha comenzado a utilizarse en Argentina como producto agrícola en forma creciente, abasteciendo actualmente entre 60,000 y 80,000 toneladas anuales, tanto como fuente de nutrición azufrada y cálcica, como para prácticas de remediación de suelos salinos sódicos. Los carbonatos son demandados para el tratamiento de suelos ácidos (corrección de $\mathrm{pH}$ cuando la diagnosis 
lo indica), una condición frecuente en la región pampeana motivada en la práctica agrícola continuada y el uso de fertilizantes de base ácida. El potasio es un nutriente esencial sobre el cual ha comenzado a alertarse de su disminución en los suelos agrícolas argentinos, naturalmente provistos de este elemento. La necesidad crítica de otro nutriente esencial, como el caso del fósforo, se hace evidente en los balances negativos de reaprovisionamiento al suelo a pesar de crecientes importaciones de fertilizantes de base química y de roca fosfórica (300,000 $\mathrm{t}$ anuales) para producción de superfosfato.

La Figura 1 expone el área agrícola argentina dividida en áreas óptimas y subóptimas y aquellas marginales y/o con necesidad de riego, así como las subregiones con deficiencias físico-químicas que requieren la aplicación de enmiendas minerales. En Herrmann y Duggan (2016) se exponen las principales aplicaciones de los minerales en suelos de cultivo y sus objetivos en la incorporación de $\mathrm{S}, \mathrm{K}, \mathrm{P}, \mathrm{Ca}, \mathrm{Mg}, \mathrm{B}$ como nutrientes y en su uso correctivo en suelos ácidos y/o salinos sódicos del país.

Se presenta entonces en Argentina una importante necesidad mineral y la existencia, aunque no completa, de recursos para cubrirlas. El presente trabajo expone las características geológicas del territorio favorables para la generación de depósitos de estos minerales y rocas (yeso, car-

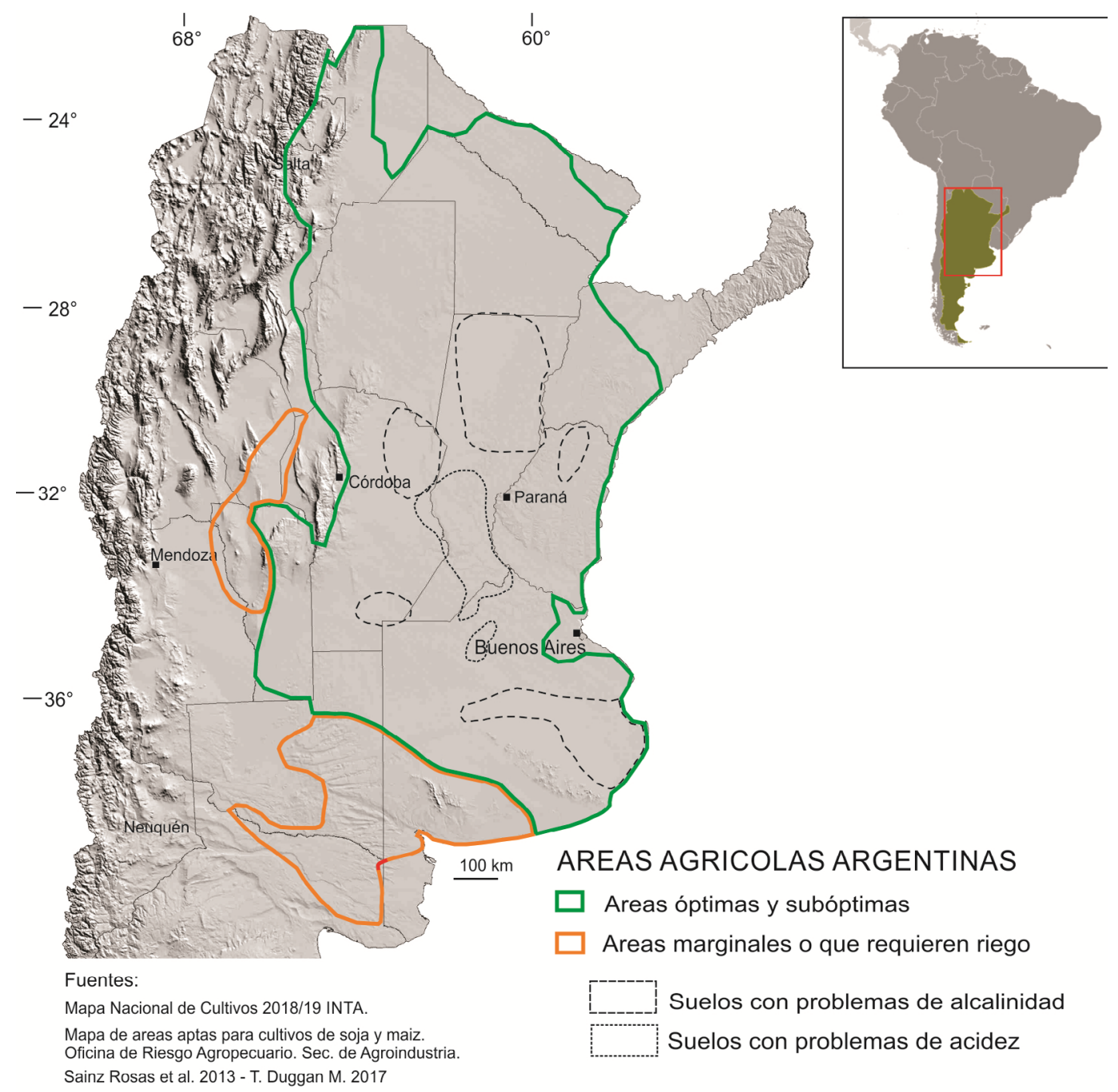


bonatos cálcicos y magnesianos, sales de potasio, rocas fosfóricas, ceolitas y boratos) y la distribución temporal y geográfica de sus depósitos y fajas litogenéticas.

\section{Recursos de Azufre (Yeso agrícola) en Argentina}

El yeso es una de las principales fuentes de azufre como nutriente agropecuario y su aplicación incorpora conjuntamente al suelo una cantidad considerable de calcio (hasta $18 \% \mathrm{~S}$ y $23 \% \mathrm{Ca}$ ).
$\mathrm{Al}$ mismo tiempo el yeso es también un importante corrector de suelos productivos. De hecho, Argentina es el tercer país afectado por suelos salinos y sódicos a nivel mundial, - con alrededor de 15 millones de hectáreas de suelos con diferente grado de salinidad y sodicidad en diferentes zonas (Torres Duggan et al., 2013) - y la prescripción de dosis de yeso para su corrección es una práctica creciente que ha comenzado a recomendarse $\mathrm{e}$ instaurarse.

Del mismo modo, sus reservas de este mineral son cuantiosas aunque la explotación de sus depósitos es función de su calidad y ubicación

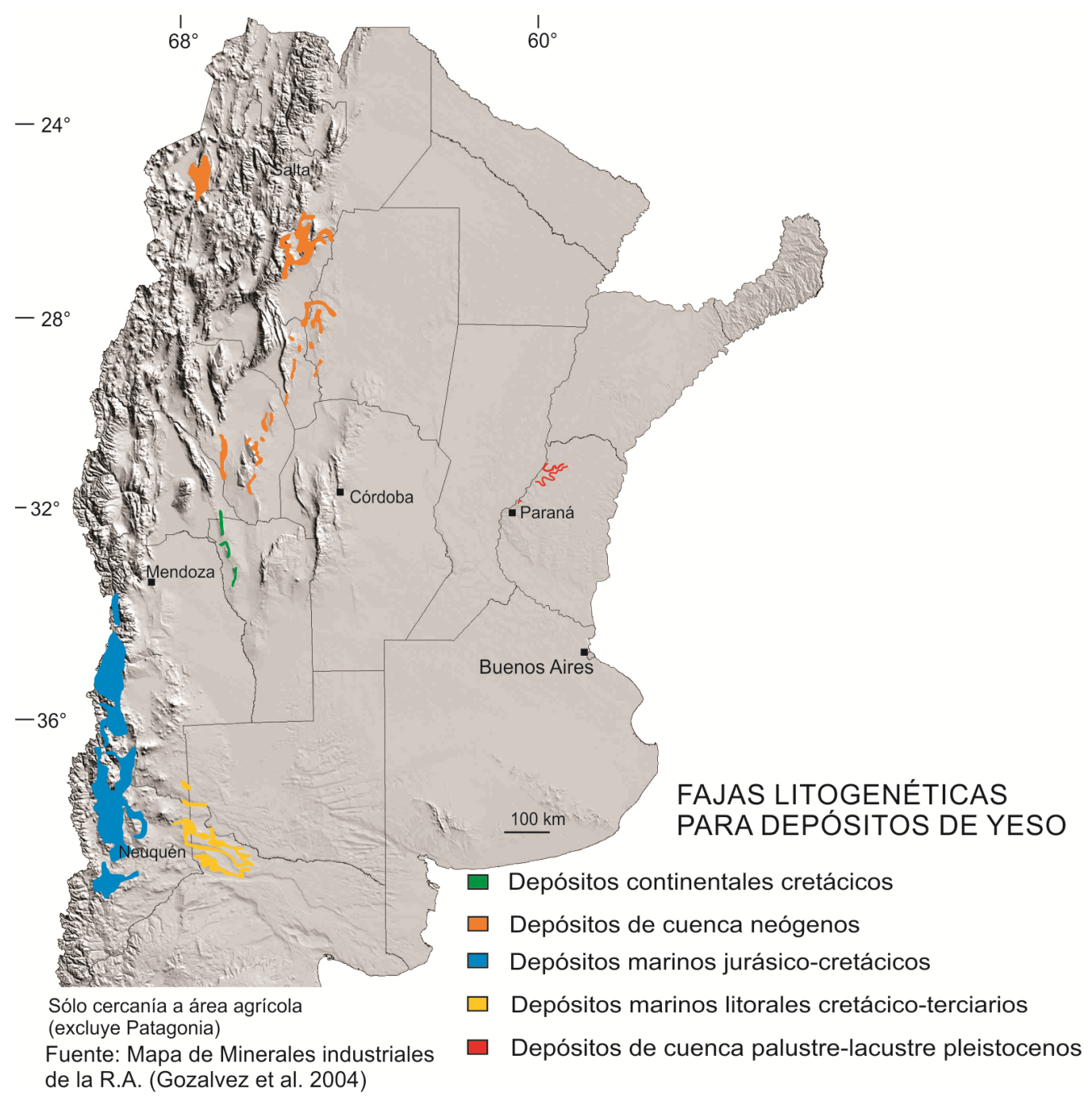

Figura 2 Distribución de las fajas litogenéticas portadoras de depósitos de yeso factibles de utilizarse como recurso agrícola en Argentina. 
geográfica. Sus yacimientos más importantes, por reservas y leyes, son los de origen marino, ubicados en la Cuenca Neuquina. Aunque también los depósitos continentales lacustres situados en cuencas intermontanas de los sectores extraandinos son muy explotados por su cercanía a los principales centros de consumo.

La Figura 2 muestra la distribución de las fajas litogenéticas con depósitos de yeso de distintas edades y ambientes de formación. Estas fajas fueron definidas en Gozalvez et al. (2004); corresponden a la sistematización de la información geológica sobre depósitos de minerales industriales, y se utilizan como una herramienta primordial en la interpretación y reconocimiento de la potencialidad de las unidades geológicas para albergar determinados modelos de depósitos (SEGEMAR, 1999).

En seguimiento a esta esquematización, en una agrupación geográfica, las cuatro regiones de Argentina con mayor potencial para la producción de yeso con destino al uso agrícola son: la Cuenca Neuquina - que abarca un sector de las provincias de Mendoza y Río Negro y casi la totalidad de la provincia del Neuquén-, el centro-oeste argentino, el suroeste de Mesopotamia y la Región Pampeana. A su vez, las principales características de estas regiones son:

a.- Cuenca Neuquina: los depósitos de yeso forman parte de unidades litológicas evaporíticas mesozoicas, como las formaciones Auquilco (Jurásico superior), Huitrín (Cretácico temprano), Allen (Cretácico superior) y Roca (Cretácico superior). Se caracterizan por ser depósitos de gran extensión y espesores variables, alcanzando potencias de hasta 300 metros en áreas deformadas tectónicamente. Sus reservas son cuantiosas y la calidad del yeso es en todos los casos superior a $80 \% \mathrm{CaSO}_{4} 2 \mathrm{H}_{2} \mathrm{O}$. La cuenca en sí cuenta con varios yacimientos en producción que desde hace varios años comenzaron a proveer las necesidades del agro, además de continuar con la provisión a la industria cementera y de la construcción en general. Dentro de Cuenca Neuquina, en la provincia de Río Negro los depósitos más importantes se encuentran en las cercanías de las localidades de General Roca y Allen; son estratos horizontales ("mantiformes") de hasta 2 metros de espesor interestratificados con arcillitas y margas de la Formación Allen (Uliana y Dellapé, 1981) y de hasta 15 metros de espesor en la Formación Roca (Uliana y Dellapé, 1981) (Figura 3b). En la provincia de Mendoza los yacimientos se localizan en los alrededores de la localidad de Malargüe; en estos el yeso se presenta en la base de la Formación Auquilco (Groeber, 1946), en estratos de color blanco o bien gris blancuzco interdigitado con lentes de anhidrita gris azulada; o bien en el sector Campo de los Militares, con espesores de hasta 30 metros, de color gris blanquecino interestratificados con lutitas y arcillitas de la Formación Huitrín (Groeber, 1946). Por su parte, en la provincia del Neuquén los depósitos de yeso forman parte de la Formación Huitrín; están ubicados en las zonas de Auquilco, volcán Tromen y la sierra de Vaca Muerta y comprenden estratos horizontales ("mantos") muy extensos de decenas de $\mathrm{km}^{2}$ de superficie con importantes espesores.

b.- Oeste y centro-oeste argentino: los sectores centro y norte occidentales del territorio argentino presentan numerosas cubetas sedimentarias, generadas principalmente durante la orogenia andina en el ámbito del antepaís. Anteriormente, estas constituyeron depocentros de ambientes continentales en áreas de clima árido a semi-árido donde se han formado depósitos de yeso de diversos tamaños, pureza e importancia económica. Litoestratigráficamente, pertenecen a la Formación Río Salí, Estratos Calchaquenses, Estratos de Los Llanos, Formación Lagarcito y Formación Las Mulitas. Sus yacimientos se han explotado históricamente como materia prima para la industria de la construcción y, específicamente, para la industria cementera. Sin embargo, por encontrarse ubicados muy cercanos o dentro de la principal área agrícola de Argentina han comenzado a abastecer al agro, no obstante constituir depósitos relativamente pequeños de calidad variable. Geográficamente, la región comprende depósitos en las provincias de San Luis, San Juan, La Rioja, Catamarca, Santiago del Estero, Tucumán y Salta. 
En general, son estratos horizontales de hasta 2.5 $\mathrm{m}$ de espesor compuestos por yeso masivo y por concreciones (denominadas "bochas" en el lenguaje local) de textura sacaroide y diámetro variable (5 a $50 \mathrm{~cm}$ ), soportadas por una matriz arcillosa, con intercalaciones de láminas de arcillitas.

Específicamente, en la provincia de San Luis, sobre el flanco sudeste de la sierra del Gigante, los depósitos están constituidos por uno o dos estratos de yeso de 0.7 a $2 \mathrm{~m}$ de espesor, de color blanco grisáceo y rojizo, con una estructura compacta a granular, e intercalados con arcillitas rojas de la
Formación Lagarcito (Flores, 1979), unidad ésta que pone fin a la depositación cretácica con una sucesión psamítica-evaporítica. Por otro lado, al sur de la capital provincial, el yeso aflora en forma discontinua a lo largo de más de $6 \mathrm{~km}$ con espesores de 1 a 2 metros, formando parte de la Formación Las Mulitas (Flores, 1979) del Mioceno medio-Plioceno inferior. Cabe destacar que de ambos sitios se ha provisto yeso para el aporte de azufre y calcio a la importante industria de cultivo de maní de la región sur de Córdoba (tercer exportador mundial de maní).

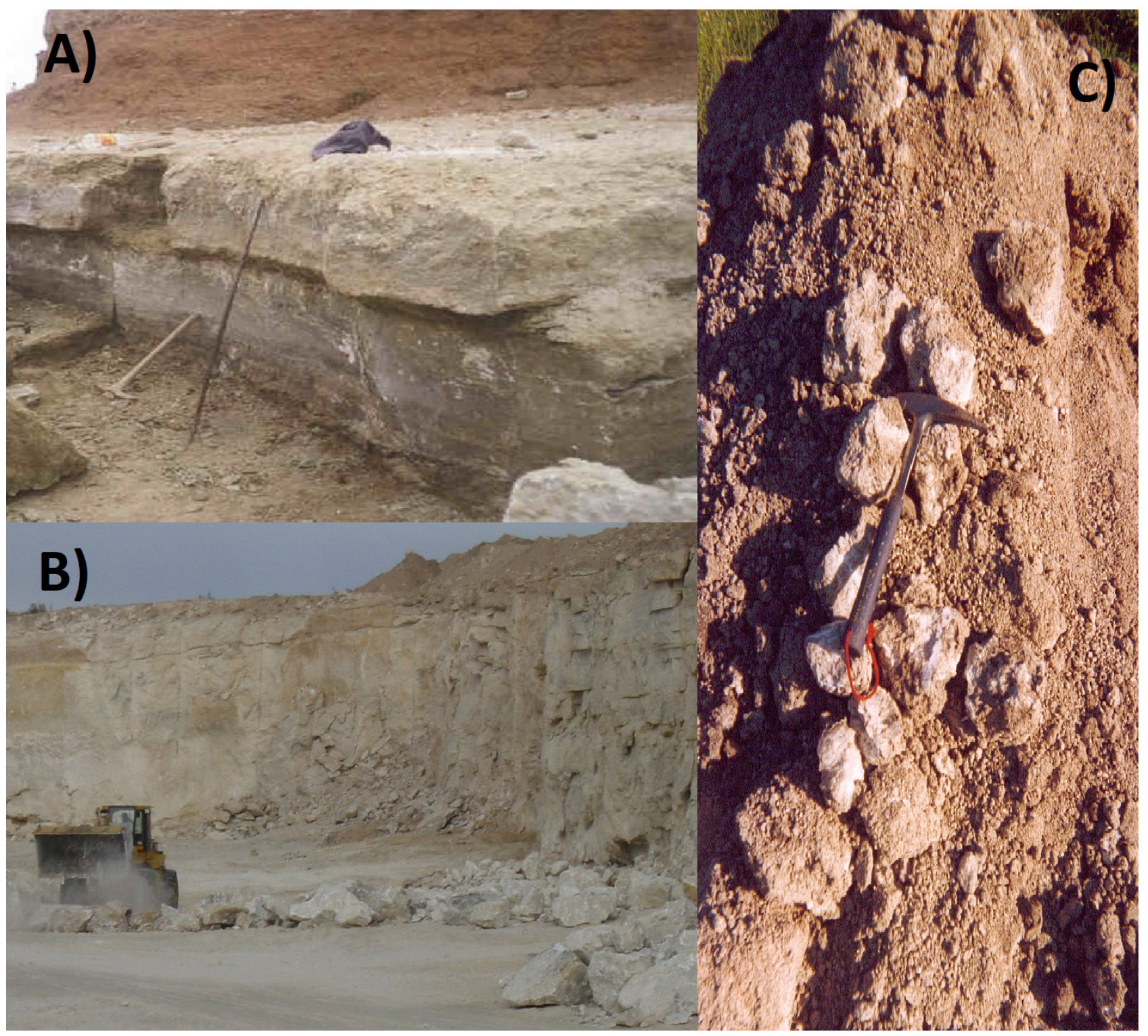

Figura 3 Ejemplos de diferentes depósitos de yeso en explotación en la República Argentina. 
Por su parte, en la provincia de La Rioja, el yeso se localiza en la cuenca de Los Llanos (desarrollada al este y oeste de la sierra homónima) lugar donde se depositaron los Estratos de los Llanos que sobresalen topográficamente entre el relleno cuaternario. En el departamento Recreo, extremo sur de la provincia de Catamarca, se explota un estrato yesífero intercalado entre sedimentitas de la misma unidad que la anterior; estos depósitos constituyen la prolongación sur de la denominada "cuenca yesífera de Santiago del Estero", donde los niveles de yeso se intercalan con arcillitas verdes miocenas. Por último, inmediatamente al norte, en las provincias de Tucumán y Salta, la cuenca de Vipos-Tapia (desarrollada al este de las Cumbres Calchaquíes y de la Sierra de La Ramada), contiene depósitos de yeso entre las limolitas arcillo-arenosas de la Formación Río Salí (Ruiz Huidobro, 1960) de edad miocena (Figura 3a).

c.- Región Pampeana: se agrupan en ella los yacimientos de yeso de las provincias de Buenos Aires y La Pampa; circunscriptos estos a depósitos cuaternarios fluvio-palustres-lacustres de ríos importantes como el Quequén Salado y Salado. Los niveles mineralizados forman parte de los sedimentos Postpampeanos, Formación Luján y Formación Lobos. Son depósitos con importantes reservas y baja ley localizados en una importante área productiva agrícola nacional; aunque su producción de yeso no es significativa debido a que varios yacimientos están cercanos al límite económico de explotabilidad.

Especificamente, en la provincia de Buenos Aires, en el arroyo El Siasgo se cubicaron 51 Mt de yeso en un área de 2,000 ha con ley de $70 \% \mathrm{CaSO}_{4} \cdot 2 \mathrm{H}_{2} \mathrm{O}$; mientras que en el arroyo Poronguito las reservas ascienden a $6.1 \mathrm{Mt}$ en un área de 246.8 ha, con un contenido de 55 $\% \mathrm{CaSO}_{4} \cdot 2 \mathrm{H}_{2} \mathrm{O}$ (Dangavs, 2001; Dangavs y Blasi, 2002). Por su parte, en los depósitos del río Quequén Salado, los contenidos de yeso son variables (entre 50 y $90 \% \mathrm{CaSO}_{4} \cdot 2 \mathrm{H}_{2} \mathrm{O}$ ) en un nivel de hasta $4 \mathrm{~m}$ de espesor, intercalado con sedimentos cuaternarios. En la provincia de La Pampa, los depósitos se ubican cercanos a la localidad de Puelches, a ambos lados del río Salado. Estos son bancos de yeso de aproximadamente $2 \mathrm{~m}$ de espesor con niveles de diferente calidad; con leyes que aumentan de base a techo (de 50-70 a 80-90\% $\mathrm{CaSO}_{4}, 2 \mathrm{H}_{2} \mathrm{O}$ ) y que se asocian a lentes de limos $\mathrm{y}$ arcillas de ambiente lacustre intercaladas en areniscas fluviales.

d.- Suroeste de Mesopotamia: sus acumulaciones de yeso con importancia económica se encuentran en la provincia de Entre Ríos y forman parte de depósitos de cuencas palustre-lacustres del Pleistoceno medio. El yeso está contenido como nódulos (Figura 3c) en un horizonte limo-arcilloso (hasta 15\% de nódulos de yeso de $15 \mathrm{~cm}$ de tamaño máximo, más concreciones y "rosetas") que forma parte de la sección basal de la Formación Hernandarias (Reig, 1957). Dicho mineral se originó en un ambiente palu-lacustre, a partir del aporte de sulfato de calcio de la Formación Paraná, unidad terciaria de origen marino muy extendida en la región (Romero y Schalamuk, 1992).

Han sido intensamente explotados y se distribuyen a lo largo de una extensa faja submeridiana a orillas del río Paraná, entre la población Piedras Blancas y el norte de Paraná, donde existe una producción sostenida de yeso. En una de las principales canteras de la zona (un pit del orden de $100 \mathrm{~m}$ de diámetro y $15 \mathrm{~m}$ de profundidad), el horizonte yesífero es de 3 a $7 \mathrm{~m}$ de espesor y subyace un nivel de suelo, loess y arcillas de hasta 8 metros.

En los extremos norte y sur del país también existen depósitos de yeso de importancia, aunque no destinados al uso agrícola debido a su alejada ubicación. En la provincia de Salta, al noroeste del salar de Pocitos, intercalado en las areniscas y limolitas grises de la Formación Pozuelos (Turner, 1960), se ha explotado un estrato de 0.6 $\mathrm{m}$ de espesor, que contiene bloques de alabastro de hasta $0.4 \mathrm{~m}^{3}$. En la Patagonia, los principales depósitos se localizan en la proximidades de la localidad de Sarmiento y al sur de la Gran Laguna Salada en la provincia de Chubut; forman parte de la Formación Salamanca (Andreis et al., 1975) del Paleoceno inferior y se caracterizan por su gran extensión areal, con estructura laminar y en algunos casos textura sacaroide, con espesores de hasta 3 metros. 


\section{Recursos de Potasio en Argentina}

$\mathrm{El}$ potasio es un nutriente principal requerido en dosis importantes, desde $20 \mathrm{~kg}$ a más de $30 \mathrm{~kg}$ de $\mathrm{K}$ por tonelada de cultivo asimismo es un requerimiento nutricional de los cinco principales cultivos en Argentina: soja, trigo, maíz, girasol y sorgo, (García y Correndo, 2016). Debido al elevado contenido natural de $\mathrm{K}$ en los suelos argentinos (reposición vs extracción $<10 \%$ ), en los últimos años han aparecido síntomas de deficiencias de $\mathrm{K}$ en suelos de determinadas zonas agrícolas del país. La silvita es la sal de potasio $\left(62 \% \mathrm{~K}_{2} \mathrm{O}\right)$ más utilizada en la agricultura, aunque en algunos cultivos la presencia de cloro es nociva. $\mathrm{El} \mathrm{K}_{2} \mathrm{SO}_{4}$ con $48 \% \mathrm{~K}_{2} \mathrm{O}$ soluble en agua también es muy utilizado. Su requerimiento masivo e indispensable lo convierte en una commodity de importancia y valor entre los minerales no metalíferos.

\subsection{POTASIO EN SALMUERAS (K-LI-B) EN GUENGAS DE LA PUNA}

Los primeros estudios e investigaciones de salmueras de la Puna argentina se llevaron a cabo en las décadas de 1970 y 1980, estando a cargo de diferentes organismos estatales. Los datos obtenidos permitieron comprobar la presencia de $\mathrm{K}, \mathrm{Li}$, B, Mg, Ca, Na, Cs, Rb en cantidades anómalas (Igarzábal y Poppi, 1980; Nicolli et al., 1982; Viramonte et al., 1984), tal como se observa en la Tabla 1 para los elementos de requerimiento agrícola potasio y boro.

La Puna es una unidad morfoestructural (o provincia geológica) caracterizada por su altura (un plateau de 3500 metros sobre el nivel del mar), extrema aridez, profuso volcanismo e hidrotermalismo activo, donde se desarrollaron cuencas endorreicas con depósitos evaporíticos con aportes volcánicos. La estructuración de estas cuencas se inició en el Paleógeno y las condiciones de aridez existen desde el Neógeno (6 Ma). Geográficamente comprende el sector oeste de las provincias de Jujuy, Salta y Catamarca.

La característica sobresaliente del Altiplano-Puna es su volcanismo orogénico cenozoico,
Tabla 1. Composición promedio de potasio, boro y litio de las salmueras de los principales salares de la Puna argentina.

\begin{tabular}{|c|c|c|c|c|}
\hline Salares & K (en g/l) & B (en g/l) & Li (en g/l) \\
\hline Olaroz-Cauchari & $\mathbf{5 . 9}$ & 1.09 & 0.71 \\
\hline Guayatayoc-Salinas Grandes & $\mathbf{9 . 8}$ & 0.23 & 0.78 \\
\hline Rincón & $\mathbf{7 . 5}$ & 0.33 & 0.4 \\
\hline Arizaro & $\mathbf{4 . 0}$ & 0.12 & 0.08 \\
\hline Pocitos & $\mathbf{4 . 8}$ & 1.32 & 0.09 \\
\hline Antofalla & $\mathbf{4 . 7}$ & 10.8 & 0.32 \\
\hline Hombre Muerto oeste & $\mathbf{6 . 3}$ & 2.06 & 0.68 \\
\hline Hombre Muerto este & $\mathbf{8 . 9}$ & 0.62 & 0.78 \\
\hline & & & \\
\hline
\end{tabular}

constituido por estratovolcanes y domos volcánicos de composición andesítica, dacítica y calderas volcánicas de grandes dimensiones asociadas a flujos ignimbríticos. Del mismo modo, se caracteriza por sus depresiones topográficas, que constituyen cuencas endorreicas, representan el nivel de base de la región además reciben depósitos coluviales y de abanicos con gravas en la base, gradando hacia arriba a mantos de arena, limos de playa, arcillas y depósitos evaporíticos.

Cada una de estas depresiones presenta características particulares que condicionan la naturaleza de los acuíferos que contienen las salmueras con Li-K-B. Se pueden agrupar en dos tipologías (Houston et al., 2011): a) Salares maduros con halita y b) Salares clásticos inmaduros. La mayoría de los salares de la Puna pertenecen a esta última.

Las salmueras alojadas en acuíferos de salares muestran un incremento en la concentración de solutos desde los márgenes al núcleo, evidenciando un "cuerpo de salmuera" con límites definidos por la zona de transición entre agua dulce y salmuera. Los salares puneños argentinos datan de 10,000 a 100,000 años de antigüedad y contienen salmueras de tipo Na-Cl-SO ${ }_{4}$. El enriquecimiento en 


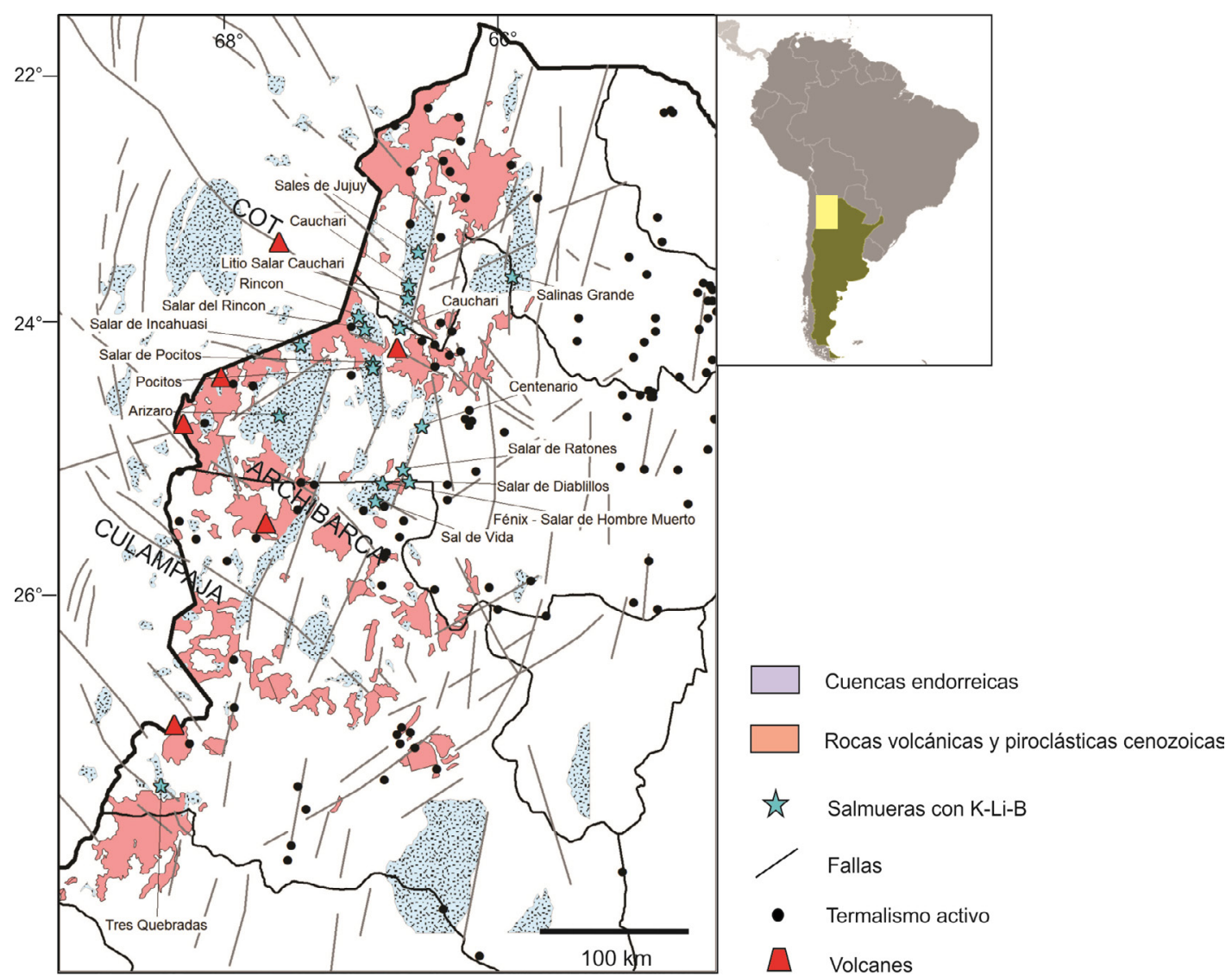

Figura 4 Ubicación de los principales elementos geológicos con los que se asocian la salmueras de K-Li-B en la Puna argentina: cuencas endorreicas, magmatismo cenozoico, campos geotermales, estructuras regionales (Segemar, 2018).

$\mathrm{K}$, al igual que en $\mathrm{B}$ y Li, no tiene un origen claramente definido, aunque Houston et al. (2011) los vinculan al Cuerpo de magma del Altiplano-Puna (Chmielowski et al., 1999); por su parte, Alonso y Viramonte (1993) sostienen que la principal fuente de aporte catiónico está relacionado con la actividad volcánica; mientras que Igarzábal (1999) concluye que la rápida ionización de los cuerpos lacustres de la Puna se debe en gran medida a la actividad volcánica, en particular a su hidrotermalismo asociado. $\mathrm{Al}$ estado de conocimiento actual los principales controles de la mineralización de $\mathrm{K}, \mathrm{Li}$ y B en salmueras son la cercanía de los salares a grandes calderas volcánicas ignimbríticas y a emanaciones termales con predominancia de aporte volcánico, mostrados en la Figura 4.

$\mathrm{El}$ auge de la exploración por litio permitió la cuantificación reciente de los recursos de los salares, entre ellos los de potasio, que alcanzan en la Puna argentina $160 \mathrm{Mt} \mathrm{K}_{2} \mathrm{O}$ como recursos totales identificados en 2018. En la Tabla 2 se presentan los datos de recursos de los salares de Cauchari, Olaroz y Diablillos. A la vez, la extracción de potasio de estas salmueras para la provisión al mercado agrícola será necesariamente un subproducto de su explotación para producir sales de litio.

Tabla 2. Datos de recursos de potasio en salmueras de la Puna Argentina.
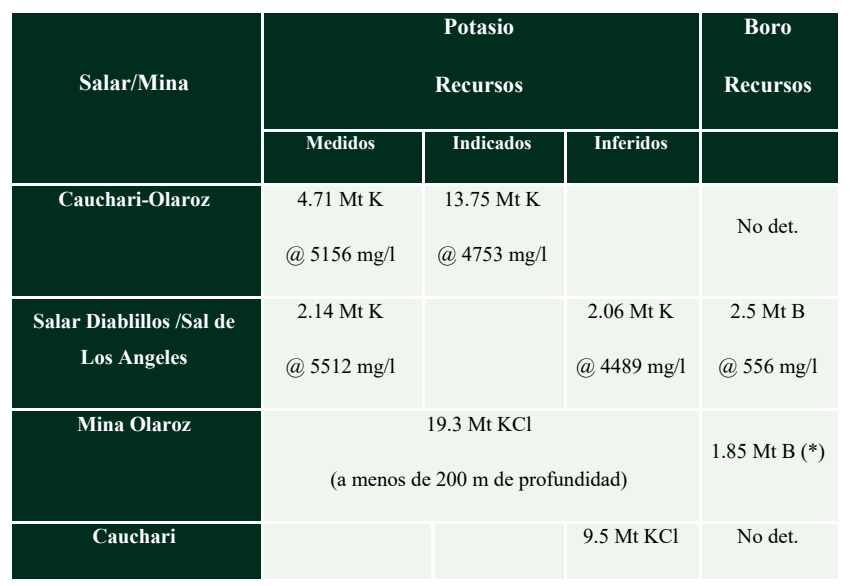

Recursos posiblemente explotables como subproducto de la extracción de Li. 


\subsection{POTASIO EN DEPÓSITOS DE SILVITA DE LA GUENCA NEUQUINA}

En la Cuenca Neuquina (sur de la provincia de Mendoza y norte de la provincia del Neuquén), formando parte de la secuencia evaporítica, se reconocen niveles salinos con $\mathrm{KCl}$ ubicados a una profundidad del orden de 1000 metros. Con su gran extensión (aproximadamente 4,000 km²), se ubica entre las más importantes del mundo por su contenido de $\mathrm{KCl}$, con recursos totales estimados del orden de 1 Gt KCl. La distribución del depocentro salino (facies de sales amargas) se observa en la Figura 5.

Los límites de subsuelo orientales están basados en el análisis de perforaciones, mientras que los occidentales están definidos por los afloramientos de la Formación Huitrín. Los niveles mineralizados con potasio se ubican en la sección superior del Miembro Troncoso de la Formación Huitrín (Barremiano - Cretácico temprano). El Miembro Troncoso superior fue dividido en varias unidades, de acuerdo con los autores que lo estudiaron. Bengochea y Padula (1993), en el área del proyecto de la empresa Potasio Rio Colorado (PRG) en el sur de Mendoza, lo dividen en: Sulfatos Basales, Sal Principal y Arcilla Guía (Figura 6). Por otro lado, Gómez et al. (2011) realizaron el análisis y correlación de datos disponibles de composiciones litológicas, mineralogía, registros geofísicos, análisis químicos, recopilación de trabajos anteriores e información de empresas mineras. De esta revisión y análisis propusieron dividirlo en 6 unidades litológicas, de base a techo: Anhidrita Basal, Halita Inferior, Silvinita K1, Halita Intermedia, Silvinita K3, Halita Superior. Por su parte, Gabriele (2016) lo separó en Facies anhidrita, Facies salina concentradora, Facies de sales amargas (portadora de silvita y halita) y Facies salina terminal.

Balod (1999) describe la información de perforaciones realizadas para el proyecto Potasio Río Colorado; destaca que los Sulfatos Basales en subsuelo conforman un cuerpo tabular de anhidrita laminar o nodular con amplia distribución en la cuenca, que constituyen un importante sello hidráulico inferior de la formación salina y en

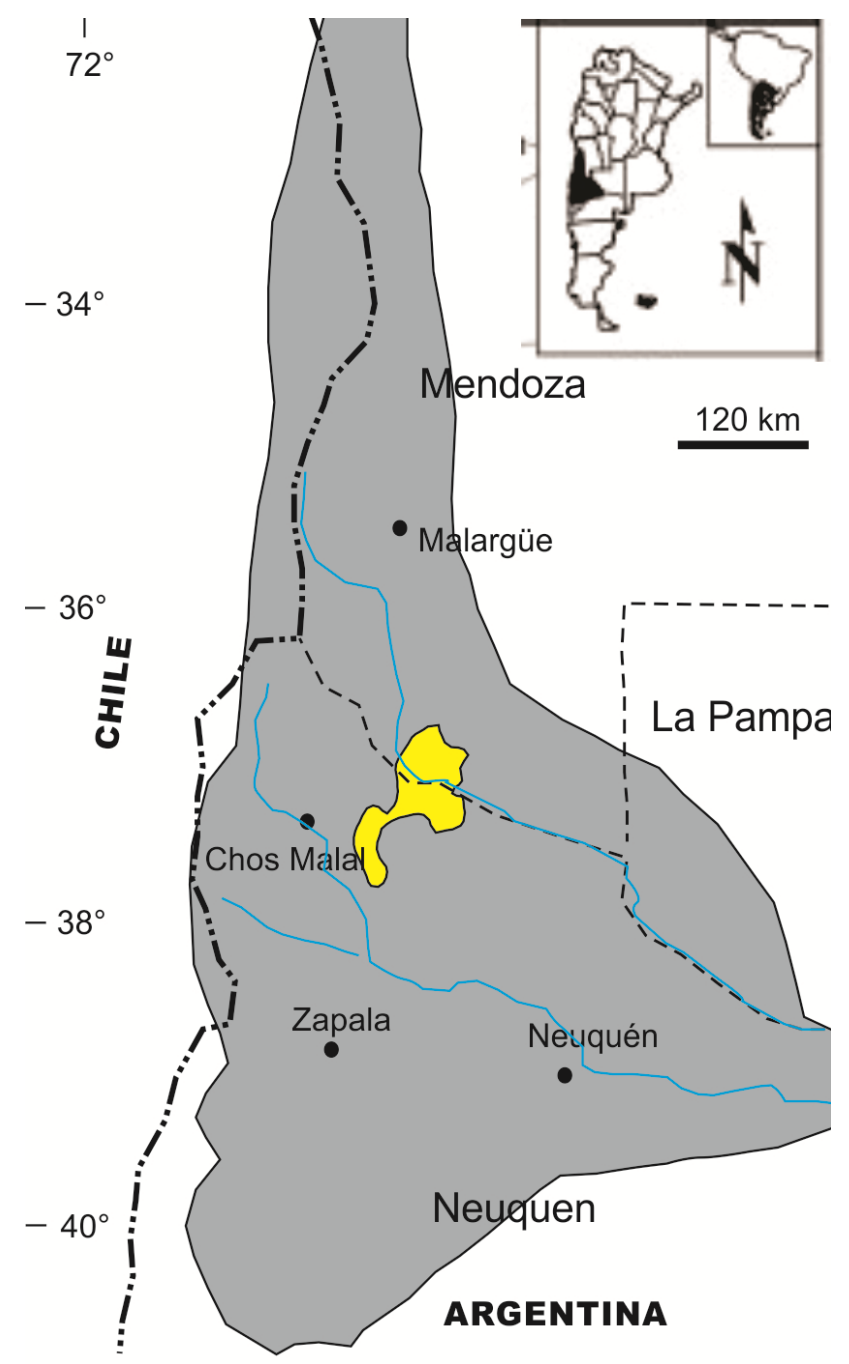

Figura 5 Ubicación (en color amarillo) de la facies evapoquímica de Sales Amargas (silvita; silvita+halita) del Miembro Troncoso superior de la Formación Huitrín en la Cuenca Neuquina, según Gabriele (2016).

superficie este nivel está representado por afloramientos de yeso. Además, indica que el horizonte de Sal Principal está integrado principalmente por cloruros de sodio y potasio con delgadas intercalaciones de anhidrita y arcillas subordinadas; y que su presencia se ha descripto sólo en subsuelo, probablemente debido a la solubilidad de las sales que lo componen. El espesor de este horizonte varía de 0 metros, en el borde de cuenca (hacia el este), hasta 200 metros (25 km hacia el oeste). De base a techo detalla para los primeros dos tercios: $70 \mathrm{~m}$ de halita pura, con escaso contenido de insolubles, a veces con intercalaciones delgadas 


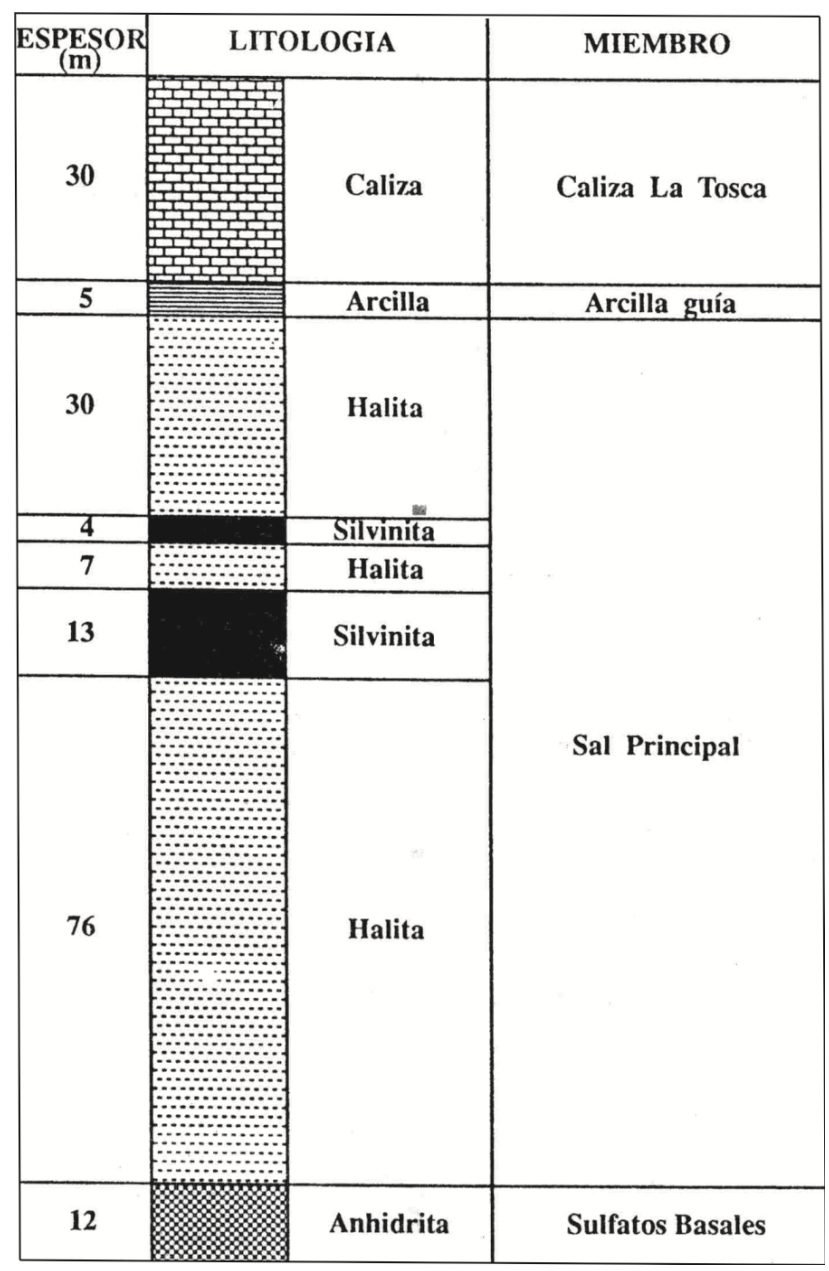

Figura 6 Perfil tipo del Miembro Troncoso Superior en el área del proyecto PRC según Bengochea y Padula (1993).

de anhidrita, y $5 \mathrm{~m}$ de halita bandeada, limpia, de color blanquecino a lechoso (intervalo Sal Inferior). En la base del tercio superior se encuentra la mineralización de potasio en una proporción de 10 a $60 \%$ de silvita $(\mathrm{KCl})$ junto con halita. Esta se distribuye en dos capas designadas como K1 y K3 (Bengochea y Padula, 1993), separadas por 5 a $8 \mathrm{~m}$ de halita con menos de $5 \%$ de silvita, conocida como Sal Intermedia. Los niveles de silvita se encuentran a profundidades cercanas a 1100 metros bajo boca de pozo (cota 220 metros sobre el nivel del mar). El tercio superior de la Sal principal, denominado Sal Superior, está integrado por $30 \mathrm{~m}$ de halita anaranjada hasta blanca lechosa y transparente, con delgadas intercalaciones de anhidrita (hasta un máximo de $60 \mathrm{~cm}$ de espesor) y de arcillas.
En la Sal Principal en las capas K1 y K3 hay presencia casi exclusiva de silvita y halita. En sentido vertical se distinguen variaciones texturales menores (tamaño y forma de los cristales, proporción de silvita y halita, color, presencia de hematita cubriendo cristales, y concentración de arcillas diseminadas). Cada una de sus capas tiene niveles de sales de potasio interestratificadas con halita estéril. La capa inferior (K1) es la más importante en el subsuelo de Mendoza (en el área del proyecto) por su continuidad lateral y regularidad de espesores y leyes.

El espesor varía entre 11 y 15 m y sus leyes son de alrededor de $25 \% \mathrm{~K}_{2} \mathrm{O}$. La capa $\mathrm{K} 3$ está separada de la $\mathrm{K} 1$ por 5 a $8 \mathrm{~m}$ de halita; su distribución areal y espesores son irregulares y su ley varía de 17 a $22 \% \mathrm{~K}_{2} \mathrm{O}$. La mineralogía que presenta es similar en las dos capas; excepto que en la K3 los cristales de silvita tienen un tamaño menor a 0.5 cm mientras que en la capa K1 los cristales son mayores $(0.5$ a $1 \mathrm{~cm}$, ocasionalmente alcanzan 5 $\mathrm{cm})$, condición que indica una posible recristalización por diagénesis que explicaría el aumento de las leyes.

También se han descripto pequeños niveles de arcillas y escasos rodados pelíticos; el contenido de insolubles (arcillas, hematita, anhidrita) en las capas con silvita es escaso ( 1 a $1.9 \%$ ).

La distribución areal del horizonte Arcilla Guía es amplia, reconociéndose en toda la cuenca, por lo que constituye un excelente nivel guía. El espesor es uniforme y varía entre 4 y 6 metros. Son fangolitas calcáreas en la base que pasan a pelitas verde grisáceas laminadas. En la zona del proyecto minero Potasio Rio Colorado el contacto con la sal principal es neto, y junto con el miembro suprayacente (Caliza La Tosca) constituyen el sello hidráulico superior de la formación salina.

En el norte de la provincia de Neuquén, la sistematización de la información disponible de sísmica y perfiles de pozos hidrocarburíferos (Figura 7) y de registros de organismos del Estado provincial permitió determinar que las áreas con niveles mineralizadas con $\mathrm{KCl}$ son: El Portón (inmediatamente al sur del río Colorado), Pampa de las Liebres (al sur de Pampa de Tril y oeste de la 


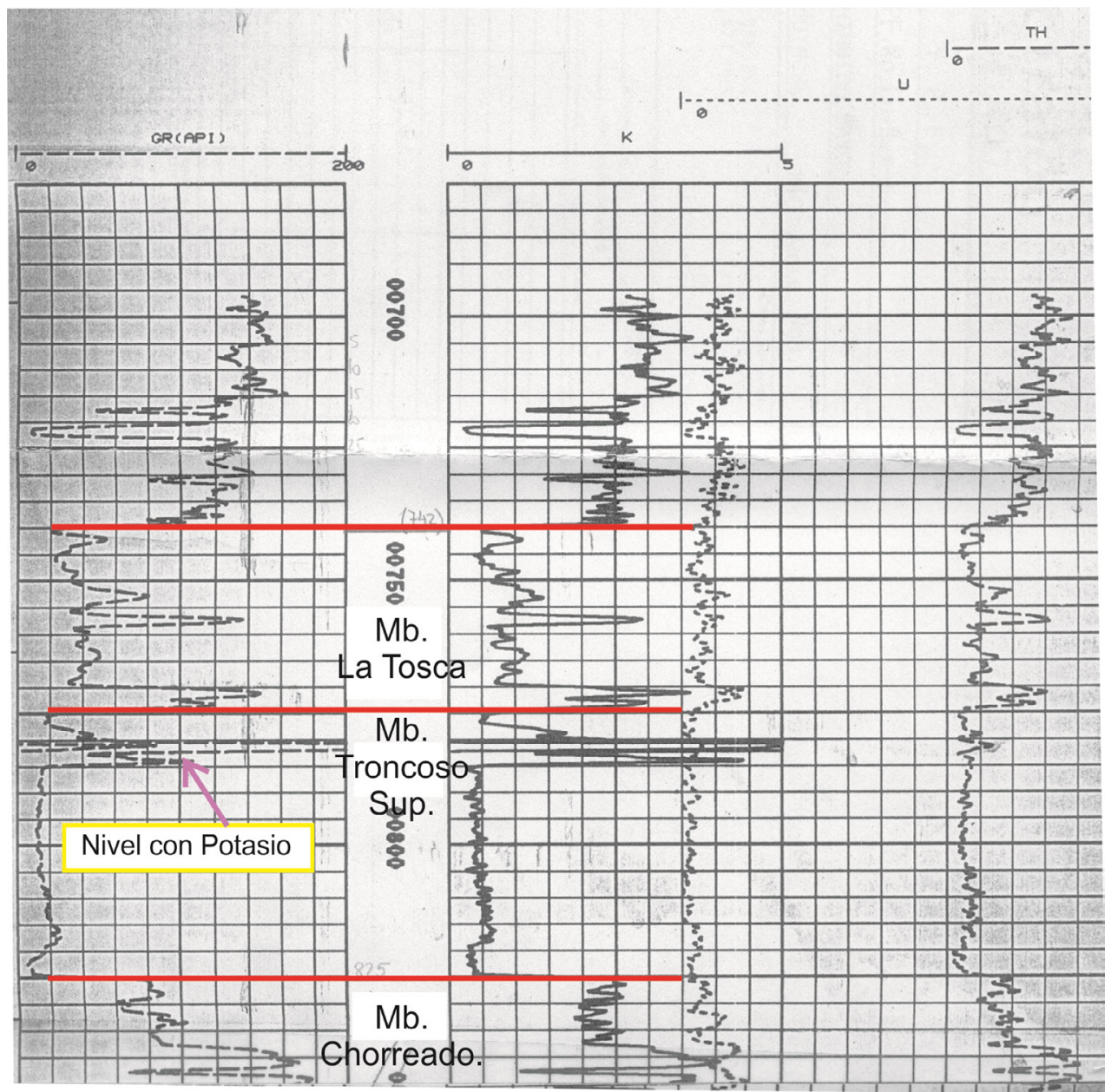

Figura 7 Detalle del perfil de rayo gamma del Pozo ChBx-1 en la provincia de Neuquén, con indicación de los picos que evidencian los niveles con potasio en horizontes del Miembro Troncoso Superior (tomado de Herrmann et al., 2003).

sierra de Huantraico), Paso Barda (flanco noroeste de la Sierra Negra hasta el río Colorado), Los Bareales y Filo Morado - Pampa Negra (Herrmann et al., 2003).

Con respecto a El Portón, hay sectores con intensa deformación tectónica que no permiten definir con claridad los niveles K1 y K3 del sector mendocino, y zonas con menos deformación donde se reconocen hasta seis niveles a una profundidad entre 700 y 1700 metros, con espesores de 4 m para el horizonte K3 y 14 m para el horizonte $\mathrm{K} 1$, y leyes inferidas del orden de $15 \% \mathrm{~K}_{2} \mathrm{O}$. En Pampa de las Liebres fueron identificados niveles mineralizados a profundidad de 600 a 700 metros bajo boca de pozo, mientras que en el flanco este de la Sierra Negra los niveles con potasio se detectaron a profundidades entre 800 y 1400 met- ros bajo boca de pozo. En el área Paso Barda se identificaron desde 2 hasta 6 horizontes con $\mathrm{KCl}$ entre 1300 y 1600 mbbp (Gabriele, 1999), con recursos estimados superiores a $100 \mathrm{Mt} \mathrm{KCl}$. En Los Barreales se definió un nivel mineralizado de $7 \mathrm{~m}$ de espesor promedio, entre 980 y 1200 metros de profundidad bajo boca de pozo.

En la provincia de Mendoza, el proyecto de Potasio Rio Colorado S.A. se encuentra construido, aunque el comienzo de la explotación se halla en espera desde hace aproximadamente 5 años. Inmediatamente al sur del río Barrancas (límite interprovincial Mendoza - Neuquén), varias áreas exploradas originariamente por la industria de hidrocarburos se encuentran actualmente concedidas a empresas mineras y de fertilizantes, con trabajos en etapas exploratorias. 


\section{Carbonatos de Calcio y Magnesio (Calizas y Dolomías) en Argentina}

Argentina es un importante productor de rocas carbonáticas cálcicas y cálcico-magnesianas para uso industrial en general, aplicando al uso agrícola mayormente las dolomías más que las calizas. Las rocas carbonáticas se utilizan en la agricultura fundamentalmente para neutralizar suelos ácidos. En Argentina se presentan limitaciones de acidez edáfica en varias regiones, con niveles críticos en las provincias de Corrientes, sur de Misiones, norte de Buenos Aires, sur de Santa Fe y de Entre Ríos, y sudoeste de Buenos Aires - este de La Pampa (Michelena et al., 1989; Gambaudo y Fon- taneto, 2011). A su vez, la utilización de calizas en granulometrías adecuadas provee $\mathrm{Ca}$ al suelo y las dolomías Mg y Ca.

Existe una distribución amplia de estas rocas en todo el territorio, ubicadas en disímiles unidades morfoestructurales (Sierras Pampeanas, Cordillera Oriental, Sierras Septentrionales de la provincia de Buenos Aires, Precordillera, Cuenca Neuquina y Macizo Norpatagónico) y fajas litogenéticas de distintas edades y ambientes de formación (Figura 8), que presentan características químicas y genéticas variadas.

Los depósitos de rocas carbonáticas se agrupan, en base a criterios de distribución geográfica, en cuatro regiones: Región Central, Buenos Aires,

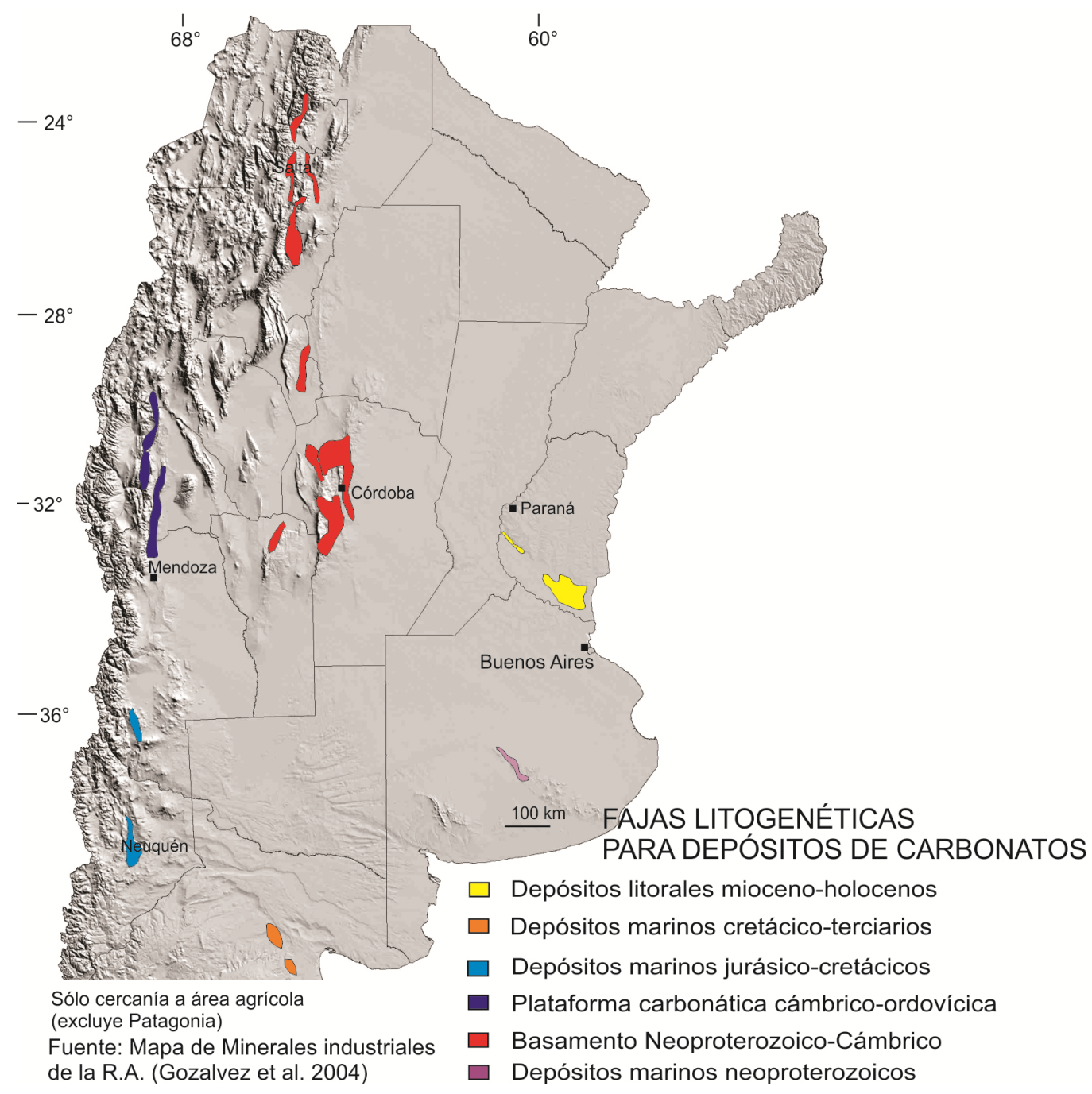

Figura 8 Distribución de las fajas litogenéticas con depósitos de calizas y dolomías factibles de utilizarse como recurso agrícola en Argentina. 
Precordillera, Cuenca Neuquina. También se consideran las acumulaciones de conchillas de la provincia de Entre Ríos (sur de la Mesopotamia argentina).

\subsection{REGIÓN GENTRAL}

Es la región más extensa; dentro de las provincias geológicas de Sierras Pampeanas, Cordillera Oriental y las cuencas mesozoicas del noroeste argentino, constituye una faja de dirección nortesur que atraviesa el sector central del país desde San Luis hasta Jujuy. La mayoría de sus depósitos son metamórficos, afloran en las sierras Chica, Grande, de Guasapampa, de Pocho y Altautina de la provincia de Córdoba; en las sierras del Gigante, de La Estanzuela, de Socoscora y Comechingones en San Luis; flanco oriental de la sierra de Ancasti (Catamarca); flanco oriental de las Cumbres Calchaquíes en Tucumán y, por último, en la quebrada de Humahuaca, en la provincia de Jujuy. Se generaron durante el Neoproterozoico y Cámbrico. Son objeto de una intensa explotación para uso en la industria del cemento y la cal en general, y de otras aplicaciones industriales en menor medida. Su excelente ubicación respecto de los requerimientos de la zona núcleo agrícola los hizo proveedor de la misma, fundamentalmente a partir de los mármoles del sur de la provincia de Córdoba, donde además de las canteras se sitúan las plantas de molienda y embolsado.

Los mármoles de la Región Central presentan gran variabilidad química. De acuerdo con su contenido en calcio y magnesio, y siguiendo la denominación de Sfragulla et al. (1999), pueden presentar tendencia calcítica (entre 30 y 52\% $\mathrm{CaO}$ y 0 a $11 \% \mathrm{MgO}$ ), dolomítica (entre 30 y $35 \% \mathrm{CaO}$ y 13 a $21 \% \mathrm{MgO}$ ) o calcodolomítica (entre 30 y $35 \% \mathrm{CaO}$ y 11 a $13 \% \mathrm{MgO}$ ). En este tipo de yacimientos el contenido de sílice puede ser alto, según el porcentaje de silicatos presentes en la roca. Consisten en cuerpos de mármol de morfología tabular o lenticular, comúnmente deformados a muy deformados y concordantes con las estructuras de las metamorfitas a las que se asocian. Las reservas de material carbonático de origen metamórfico son superiores a mil millones de toneladas (Bonalumi y Sfragulla, 2010).

Con respecto al resto de los yacimientos de esta región, se encuentran en las provincias norteñas de Jujuy y Tucumán, son de origen sedimentario y de edades cretácicas y terciarias. Los depósitos de rocas carbonáticas de origen sedimentario en el noroeste argentino afloran en la quebrada de Humahuaca (cantera Maimará) y en la sierra de Puesto Viejo (Mojón-Cerro Plano), a 74 km al norte y $55 \mathrm{~km}$ al sur de la ciudad de San Salvador de Jujuy, respectivamente. Son depósitos de calizas masivas, calizas oolíticas y areniscas calcáreas pertenecientes a la Formación Yacoraite (Cretácico superior-Paleoceno); la secuencia carbonática tiene hasta $10 \mathrm{~m}$ de espesor e importante extensión areal, con bancos calizos de hasta 1,5 m de potencia y 80 a $87 \% \mathrm{CaCO}_{3}$. Por su parte, la Formación Yacoraite (Turner, 1959) del Subgrupo Balbuena (unidad intermedia del Grupo Salta) es la unidad que alcanzó mayor dispersión areal en la ingresión maastrichtiana-paleocena. Corresponde a depósitos marinos calcáreos tabulares (calizas y calizas estromatolíticas), y presenta sectores dolomíticos, con pelitas y areniscas, además de tobas y volcanitas (Salfity y Marquillas, 1999). Asimismo, su amplia distribución en el noroeste argentina definió la "cuenca Yacoraite", que representa una depresión intracontinental, carbonática restringida, somera y alejada de las influencias del mar abierto.

Finalmente, en la provincia de Tucumán, al pie de las laderas oeste y este de las sierras de La Ramada, del Campo y Medina, afloran depósitos de calizas oolíticas en bancos de hasta $2 \mathrm{~m}$ de espesor interestratificados con pelitas verdosas y arcillitas blancas de la Formación Río Salí (Mioceno), generada en un ambiente continental lagunar.

\subsection{BUENOS AIRES}

La provincia de Buenos Aires es una de las más importantes productoras de rocas carbonáticas de la Argentina. Sus depósitos fueron formados en un ambiente marino de plataforma epicontinental durante el Neoproterozoico. Sus yacimientos, 
depósitos tanto de dolomías como calizas, se localizan en las Sierras Septentrionales, en las inmediaciones de las localidades de Olavarría y Barker.

Los primeros pertenecen a la facies dolomítico-pelítica de la Formación Villa Mónica del Grupo Sierras Bayas (Poiré, 1993; Iñiguez, 1999). Son estratos horizontales de hasta $30 \mathrm{~m}$ de espesor, con color castaño claro, estructura laminar, estromatolítica en ocasiones, con un contenido de sílice de 1.7 a $2.3 \%$ en los sectores medios y de 9 a 12\% en la base y el techo. Se explotan como áridos o bien en bloques para revestimientos ornamentales; fueron objeto de explotación en la industria siderúrgica varias décadas atrás y luego en la industria del vidrio; además, desde varios años atrás proveen a la industria agrícola aprovechando su ubicación geográfica favorable.

Los yacimientos de calizas presentan mucha mayor distribución areal y forman parte de la Formación Loma Negra, la cual está constituida por facies carbonáticas grises oscuras, negras y rojizas con niveles clásticos en su porción basal y materia orgánica en su parte superior, y culmina el Grupo Sierras Bayas. Son depósitos intensamente explotados, utilizados en la elaboración de cemento y cal para construcción. Los estratos de calizas que los conforman tienen espesor medio de 40 metros, su color es negro a pardo rojizo oscuro y están formados de micrita y subesparita con contenido de limo menor a $1 \%$ y 65 a $92 \%$ $\mathrm{CaCO}_{3}$.

\subsection{PRECORDILLERA}

Esta región abarca los cordones precordilleranos Oriental y Central de las provincias de San Juan y Mendoza. Los depósitos forman parte de una extensa plataforma carbonática formada durante el Paleozoico inferior y exhumada por la tectónica andina. Componen una importante sucesión estratigráfica, predominantemente carbonática, depositada en ambiente de plataforma interna, cuyo borde de plataforma y talud continental se ubicaban hacia el oeste (Bordonaro, 1999). Esta distribución de facies es válida para el Cámbrico y Ordovícico inferior.
Los yacimientos sanjuaninos se distribuyen en las regiones de Jáchal, Villicum y alrededores y sur de San Juan capital, constituyendo un importante y valorable recurso de calizas y dolomías (del orden de cientos de millones de toneladas) en explotación continua por más de cuatro décadas hasta la actualidad. Los espesos estratos de calizas (Figura 9) pertenecen a la formación cámbrica La Laja (Borrello, 1962) y a las ordovícicas La Silla (Keller et al., 1994) y San Juan (Amos, 1953). Por su parte, los de dolomías son de edad cámbrica y pertenecen a las formaciones Zonda (Bordonaro, 1980) y La Flecha (Armella, 1989), en un arreglo estratigráfico de 2800 metros de espesor.

La roca carbonática que contienen es de muy alta calidad, se utiliza en la fabricación de cales industriales (cálcicas y magnesianas) y en las industrias siderúrgica, papelera, cristalería, tratamiento de aguas, minera y cerámica, además de cal para la construcción; su provisión a la industria agrícola es de poco volumen debido fundamentalmente a la distancia a los sitios de consumo y comercialización, y con preferencia en las dolomías. De hecho, en el norte de Mendoza los depósitos de calizas son más escasos y forman parte de la Formación San Juan. La caliza se presenta en bancos de gran homogeneidad textural y continuidad areal; son de color gris (varias tonalidades), grano fino a sacaroide con algunas intercalaciones de ftanita y desarrollo de vetas de calcita.

\subsection{GUENGA NEUQUINA}

La Cuenca Neuquina constituye una de las principales cubetas sedimentarias formadas en territorio argentino; su historia geológica está caracterizada por presentar varios ciclos sedimentarios en donde se reconocen depósitos de ambiente marino y continental. Los mantos de calizas de interés económico pertenecen al Miembro Los Catutos de la Formación Vaca Muerta (Weaver, 1931) del lapso Tithoniano temprano a Berriasiano tardío, y a la Formación Picún Leufú (Leanza, 1973), del límite Jurásico-Cretácico; ambos facies sublitorales de la ingresión caloviana, en un mar cálido y poco profundo. 

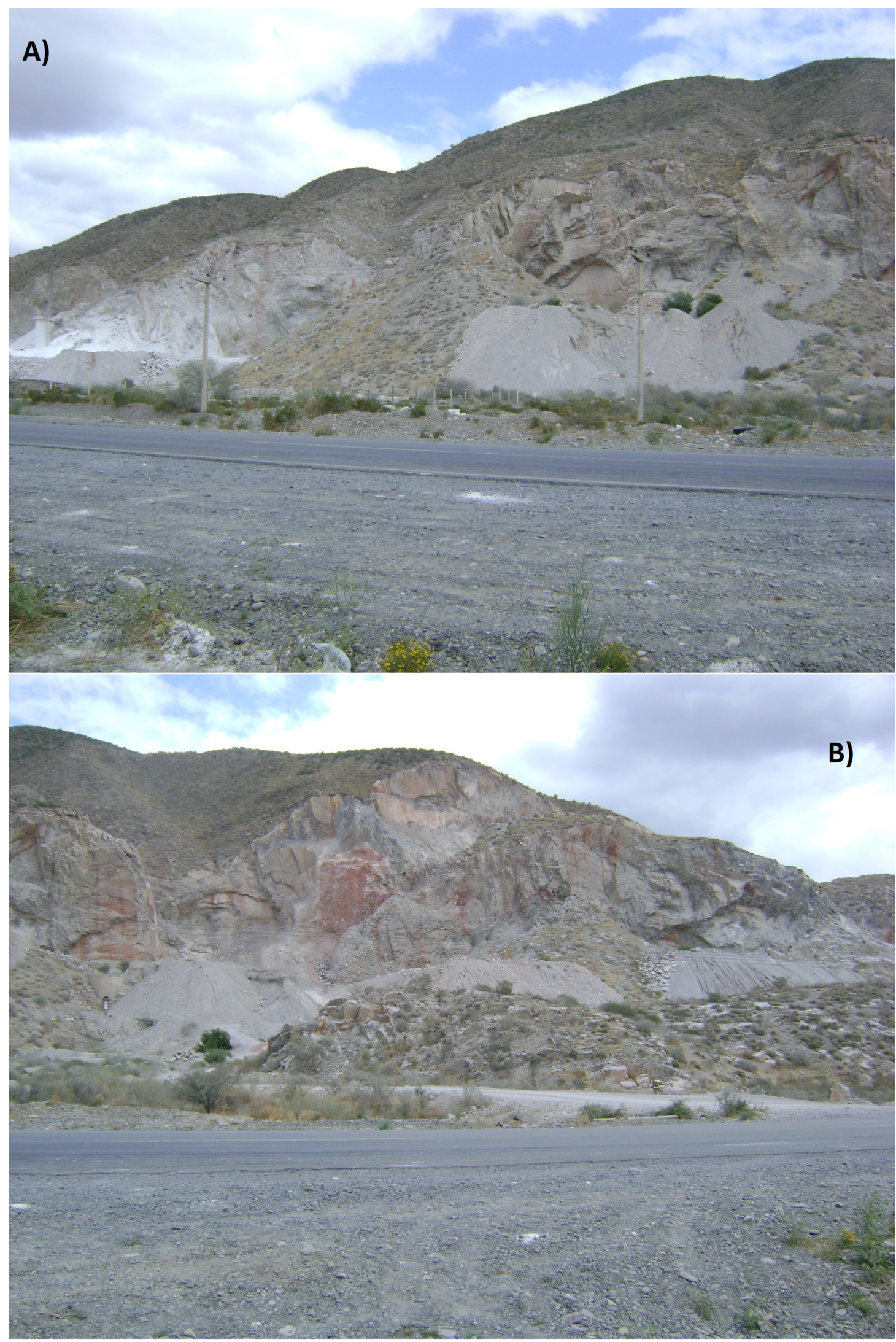
Sus depósitos se localizan en las inmediaciones de Zapala y en la región de Vaca Muerta, provincia del Neuquén. En Zapala se destacan dos zonas: 1) Pichi Moncol con estratos de calizas litográficas de entre 0.5 y $1.5 \mathrm{~m}$ de espesor intercalados entre arcillitas y margas del Miembro Los Catutos y 2) Picún Leufú con bancos de calizas detríticas fosilíferas en estratos de 0.2 a 1.6 m de espesor de la Formación Picún Leufú. En Vaca Muerta, los depósitos de calizas están formados por restos coralinos en parte silicificados de la Formación Vaca Muerta reconocidos a lo largo de una faja de $6.5 \mathrm{~km}$ de largo y $2 \mathrm{~km}$ de ancho, con $30 \mathrm{~m}$ de espesor máximo. En esta provincia se han desarrollado dos proveedores del mercado agrícola nacional y de exportación al vecino Chile.

\subsection{ENTRE RÍOS}

En la provincia de Entre Rios existen acumulaciones de carbonatos de origen orgánico, pertenecientes a la Formación Pueblo Brugo (Gentili y Rimoldi, 1979), una de las unidades de la ingresión marina del paranaense (Mioceno superior - Plioceno medio). Los yacimientos son un "calcáreo fosilífero" constituido por restos de conchillas, valvas y caparazones de moluscos marinos. También se los denomina "bancos ostreros". En ocasiones se encuentran cementados por materiales provenientes de su propia disolución, junto con sílice y arcillas; tienen espesor variable y máximo de $6 \mathrm{~m}$ aunque su promedio es de 1 metro, y son discontinuos arealmente.

Las posteriores ingresiones sanborombonense y querandinense conformaron depósitos de conchillas de la Formación Talavera (Holoceno) que se disponen como un cordón que se extiende en la región deltaica desde Gualeguaychú, conformando un arco que pasa por el arroyo Nancay, Médanos y al oeste de Puerto Ruiz.

Los depósitos de carbonatos se ubican en los departamentos del sur de la provincia: Colón, Concepción del Uruguay, Gualeguaychú, Islas del Ibicuy, Rosario de Tala, Victoria y Diamante. En el departamento Paraná, las reservas explotables se consideran agotadas (el horizonte calcáreo se encuentra a varias decenas de metros de profundidad). En épocas de producción, el material de buena calidad era separado mecánicamente (conchillas de arcillas), zarandeado, molido, secado y embolsado. La calidad es muy variable; el contenido de $\mathrm{CaO}$ puede alcanzar $50 \%$ en la producción de materiales muy bien seleccionados, aunque son más comunes de 30 a 50\% $\mathrm{CaO}$; la sílice varía de 1\% en los mejores materiales molidos hasta $30 \% \mathrm{SiO}_{2}$ en los depósitos de peor calidad.

Alejados de la posible provisión como recurso agrícola, en la Patagonia argentina también afloran rocas carbonáticas que constituyen depósitos de importancia intensamente explotados desde hace varias décadas. Sobre la costa marítima oriental en Bahía Bustamante se depositaron bancos subhorizontales de coquinas de hasta $10 \mathrm{~m}$ de espesor pertenecientes a la Formación Bustamante de edad maastrichtiana (Ardolino, 1980; Ardolino et al., 1998); un registro del brazo de mar que ingresó desde el Golfo de San Jorge.

\section{Recursos de Fósforo en Argentina}

En Argentina se prospectaron regionalmente recursos fosfáticos durante la realización del denominado "Plan Fosforita", llevado a cabo por el estado nacional hace 50 años a través de la Dirección Nacional de Geología y Minería. Iniciativas posteriores correspondieron a grupos de investigación de universidades. Entre estas se destaca la Facultad de Ciencias Exactas y Naturales de la Universidad de Buenos Aires (grupo "Fosfatos"), con aportes significativos fundamentalmente en el estudio sistemático y nuevos descubrimientos en los depósitos ordovícicos del noroeste argentino (Castro et al., 2009, 2011); así como las investigaciones de Moya et al. (2012) que propusieron un esquema de yacencia y distribución de los fosfatos ordovícicos en el norte argentino en base al desarrollo paleogeográfico de la cuenca y a la ubicación paleogeográfica temporal y espacial de los depósitos que los contienen.

Otros aportes relevantes al conocimiento de la presencia de fosfatos en Argentina lo constituyen 
la prospección sistemática de los niveles marinos cretácicos y terciarios en Patagonia, efectuada por proyectos de investigación de la Universidad de Buenos Aires, y las investigaciones sobre el posible aprovechamiento de la mena ferrífera de Sierra Grande en la provincia de Río Negro, para la obtención de apatita.

Sin embargo, los estudios puntuales de carácter minero para ampliar estos conocimientos fueron muy escasos, motivo por el que actualmente sólo se reconocen áreas con perspectivas de existencia de depósitos fosfáticos, que no permiten definir verdaderos yacimientos de fosforitas (en el sentido de depósitos económicamente explotables) sino sólo manifestaciones de rocas portadoras de fosfatos en distintas proporciones, que en su mayoría no superan $10 \% \mathrm{P}_{2} \mathrm{O}_{5}$ para volúmenes en la gran mayoría de los casos no definidos. No obstante, debe destacarse que las investigaciones han permitido definir los períodos fosfogénicos presentes en el territorio argentino, lo que aporta datos valiosos para la prospección.

Otros estudios, éstos con carácter tecnológico, se enfocaron en la recuperación de fósforo a partir de menas de minerales no fosfáticos que portan $\mathrm{P}$ como impureza, como el caso de las "colas" del procesamiento de mineral de hierro de la mina Sierra Grande en la provincia de Rio Negro (se alcanzaron concentraciones de hasta $8 \% \mathrm{P}_{2} \mathrm{O}_{5}$ ), aunque la explotación actual de este depósito ferrífero no realiza esta separación. Asimismo, fue ensayado el tratamiento de concentraciones fosfáticas del depósito Cargadero Chauque (Rio Capillas), en la provincia de Jujuy, resultando contenidos elevados de $\mathrm{P}_{2} \mathrm{O}_{5}$ soluble en medio cítrico.

\subsection{FOSFATOS EN LA GUENGA NEUQUINA, PROVINGIA DE NEUQUÉN}

Los niveles fosfáticos más conspicuos se ubican en la Sierra de Vaca Muerta y adyacencias. Están contenidos en una faja de 80 a $120 \mathrm{~m}$ de espesor en la sección superior de la Formación Vaca Muerta, con una "corrida" de $22 \mathrm{~km}$ comprendida entre el cerro Punta Alta al norte y Mallín Quemado al sur, destacándo el área de Bajada del Agrio como la más importante (Leanza et al., 1975; Mastandrea et al.,
1982). Las potencias y leyes de los niveles fosfáticos no permiten considerar su explotación económica hasta tanto no se definan continuidades de mucho mayor extensión que las reconocidas hasta el momento, con contenidos de fósforo iguales o superiores. Los sectores de la Sierra de Vaca Muerta con niveles fosfáticos identificados se encuentran: a) en Mallín Quemado; b) en La Porfía y Bajada Vieja; c) al norte del río Agrio, en la región del cerro Punta Alta (Mastrandrea et al., 1982), ver Tabla 3.

Las rocas portadoras de fosfatos son calizas fosfáticas y areniscas fosfáticas. En las primeras (micritas y subesparitas fosilíferas, oolíticas, terrígenas y nodulares), el mineral fosfático se presenta como nódulos, restos fósiles reemplazados, fragmentos clásticos, oolitas y oolitas superficiales, e impregnando la calcita micrítica, al integrar entre 2 y 40 $\%$ de la roca. En las areniscas fosfáticas (cuarzosas, feldespáticas y fosilíferas), el fosfato se encuentra como nódulos, fragmentos clásticos, restos fósiles reemplazados, cemento, e impregnando la matriz, constituyendo entre 5 y 30\% del armazón de la roca o hasta $20 \%$, cuando representa el cemento (Mastandrea et al., 1982).

La posición estructural de los niveles con fosfatos hasta ahora reconocidos no es la más conveniente para su explotación, inclinando entre 15 y $50^{\circ} \mathrm{ESE}$, en dirección contraria a la de la pendiente. En Bajada del Agrio se han explotado a muy pequeña escala bancos de hasta $50 \mathrm{~cm}$ de espesor de calizas fosfáticas, con una ley que puntualmente alcanza $10 \% \mathrm{P}_{2} \mathrm{O}_{5}$.

\subsection{FOSFATOS EN LA PROVINGIA DE GHUBUT}

La presencia de fosfatos en varias formaciones de esta provincia se reconoce a partir de las investigaciones de Leanza et al. (1981) y por posteriores de Scasso et al. (1996, 1998), Castro et al. (1996, 2004) y Tourn et al. (2004).

En rocas de la Formación Patagonia (Franchi, 1977), se reconocen concreciones fosfáticas aisladas con leyes de 10 a $19 \% \mathrm{P}_{2} \mathrm{O}_{5}$ que afloran en Punta Loma y Bajo Hondo, en el NE de la provincia de Chubut, y en Pico Salamanca, Cerro Chenque y Estancia Busnadiego, en el SE de la misma provincia. En la Formación Rio Chico (Andreis et 
Tabla 3. Niveles fosfáticos de la Formación Vaca Muerta.

\begin{tabular}{|r|c|c|c|}
\hline Localidad & Niveles fosfáticos & Espesor (m) & Ley $\left(\mathbf{\%} \mathbf{P}_{\mathbf{2}} \mathbf{O}_{\mathbf{5}}\right)$ \\
\hline Mallín Quemado & 12 & 0.30 a 0.90 & 1.8 a 5.4 \\
\hline Bajada del Agrio & 6 & 0.20 a 4.00 & 1.5 a 10 \\
\hline Co. Punta Alta & 7 & 0.10 a 0.50 & 1 a 3.8 \\
\hline La Porfía & 5 & 0.15 a 0.30 & 2.1 a 5.4 \\
\hline
\end{tabular}

al., 1975), de edad paleocena superior, se hallaron concreciones fosfáticas con leyes de 15 a $22 \% \mathrm{P}_{2} \mathrm{O}_{5}$ y en la Formación Salamanca, del Paleoceno inferior, existen manifestaciones fosfáticas con contenidos semejantes de $\mathrm{P}_{2} \mathrm{O}_{5}$. En la Formación Gaiman (Haller y Mendía, 1980), de edad miocena, aflorante en la margen derecha del río Chubut en la localidad de Loma Blanca, se reconoció una arenisca conglomerádica fosfática de 0.20 a 0.40 $m$ de potencia portadora de concreciones fosfáticas de color rosado, cementada por carbonatos, cuyo análisis - para material seleccionado- indicó un contenido de $19.50 \% \mathrm{P}_{2} \mathrm{O}_{5}$ con $29.6 \% \mathrm{CaO}$ (Castro et al., 1996; Scasso et al., 1998). Los análisis químicos de dos muestras de las concreciones indicaron 15.61 y $20.25 \% \mathrm{P}_{2} \mathrm{O}_{5}$ con $38.60 \% \mathrm{CaO}$, mientras que una muestra total del conglomerado fosfático arrojó $3.10 \% \mathrm{P}_{2} \mathrm{O}_{5}$ y $36 \% \mathrm{CaO}$.

En la Formación Lefipán (Lesta y Ferello, 1972), en el valle medio del río Chubut, el fosfato se concentra en concreciones, asociadas con trazas fósiles, y como reemplazo de restos de conchillas y restos vegetales (Fazio et al., 2013). El contenido de fosfato en estas concreciones es muy variable, desde 1 a $26 \% \mathrm{P}_{2} \mathrm{O}_{5}$, mientras que en la roca de caja (areniscas y pelitas) varía entre 0.2 y $2 \% \mathrm{P}_{2} \mathrm{O}_{5}$. La Formación está compuesta por areniscas y pelitas con intercalaciones de coquinas y conglomerados que se acumularon en ambientes estuáricos y deltaicos con fuerte influencia de mareas.

\subsection{FOSFATOS EN LAS PROVINGIAS DE SANTA GRUZ Y TIERRA DEL FUEGO}

Las rocas de la Formación San Julián (areniscas coquinoideas del Eoceno superior-Oligoceno infe- rior) poseen niveles fosfáticos delgados con leyes fluctuantes entre 1.3 y $14 \% \mathrm{P}_{2} \mathrm{O}_{5}$. Si bien afloran en varios sitios de la provincia de Santa Cruz, entre ellos el Gran Bajo de San Julián, su escaso espesor y su carácter lenticular desalientan su explotación económica.

En la Formación Rio Claro (Paleoceno-Eoceno), en el centro de Tierra del Fuego, al norte del lago Fagnano, en uno de los bancos superiores de la coquina existen nódulos irregulares de tamaño variable entre 2 y $10 \mathrm{~cm}$, cuyo análisis para material seleccionado indicó 21\% $\mathrm{P}_{2} \mathrm{O}_{5}$ y 32 \% CaO (Olivero et al., 1998).

\subsection{FOSFATOS EN LAS PROVINGIAS DE SALTA Y JUJUY (NOROESTE DE ARGENTINA)}

En varias localidades de las provincias de Salta y Jujuy se han reconocido rocas con contenido de fosfatos (areniscas cuarcíticas de edad ordovícica que alojan restos de conchillas del braquiópodo Lingula sp.), entre ellas:

a) Ríos Condado (Santa Rosa) - La Misión: un horizonte principal de $1.10 \mathrm{~m}$ de potencia con $11 \% \mathrm{P}_{2} \mathrm{O}_{5}$ y dos secundarios de 0.60 y $0.30 \mathrm{~m}$ con $7.20 \%$ y $4.8 \% \mathrm{P}_{2} \mathrm{O}_{5}$ respectivamente.

b) Ríos Porongal, Alisar e Iruya: horizontes de 0.5 a $1.20 \mathrm{~m}$ de potencia con tenores de 6 a $12 \% \mathrm{P}_{2} \mathrm{O}_{5}$.

c) Río Negro: cuatro bancos fosfáticos con espesores de 0.80 a $1.60 \mathrm{~m}$ y contenidos de 4 a 5 $\% \mathrm{P}_{2} \mathrm{O}_{5}$.

d) Río Margarita-San Lucas: un nivel de $3.5 \mathrm{~m}$ de espesor con $5.3 \% \mathrm{P}_{2} \mathrm{O}_{5}$ y otro de $2.5 \mathrm{~m}$ con $14 \% \mathrm{P}_{2} \mathrm{O}_{5}$.

e) Río Ocloyas: un horizonte de $0.80 \mathrm{~m}$ de espesor con $7.5 \% \mathrm{P}_{2} \mathrm{O}_{5}$ y otros de 1 y $2 \mathrm{~m}$ con contenidos inferiores a 5\% $\mathrm{P}_{2} \mathrm{O}_{5}$.

f) Río Capillas: En Cargadero Chauque (al NE de San Salvador de Jujuy) aflora un horizonte con $3 \mathrm{~m}$ de potencia media, $1000 \mathrm{~m}$ de extensión y contenidos de hasta $6 \% \mathrm{P}_{2} \mathrm{O}_{5}$; en Lajas Moradas (también al NNE de San Salvador de Jujuy) un horizonte de areniscas cuarcíticas fosfáticas y pelitas con una potencia de 3 metros, corrida de $650 \mathrm{~m}$ y contenido de $5 \% \mathrm{P}_{2} \mathrm{O}_{5}$.

g) Azul Pampa y alrededores de Iturbe, en el departamento Humahuaca: formando 
parte de las formaciones ordovícicas Casayoc y Azul Pampa, existen niveles fosilíferos fosfáticos de 0.20 a $0.50 \mathrm{~m}$ de espesor con contenidos que varían entre 1.5 y $7 \% \mathrm{P}_{2} \mathrm{O}_{5}$, con sitios puntuales de hasta $12 \% \mathrm{P}_{2} \mathrm{O}_{5}$ (Fernández, 1983).

Las áreas de prospección más promisorias, de acuerdo con Moya et al. (2012), se ubican en el flanco oriental de la Cordillera Oriental (donde se registran sucesiones completas de edad tremadociana) y, en menor medida, en las Sierras Subandinas. En la sucesión ordovícica de la sierra de Mojotoro, extremo SE de la Cordillera Oriental, Moya et al. (2012) definieron seis intervalos de fosfogénesis, contenidos dentro de las formaciones Floresta, Áspero, San Bernardo, Mojotoro y Santa Gertrudis, cuyos contenidos de fósforo fueron ubicados en tres rangos $\left(2\right.$ a $8 \% \quad \mathrm{P}_{2} \mathrm{O}_{5} ; 8$ a 18 $\% \mathrm{P}_{2} \mathrm{O}_{5} ;>18 \% \mathrm{P}_{2} \mathrm{O}_{5}$. Las litologías de interés corresponden a a) conglomerados bioclásticos fosfáticos-cuarzosos; b) acumulaciones residuales y c) conglomerados bioclásticos calcáreos-fosfáticos.

\subsection{OTRAS MANIFESTACIONES FOSFÁTICAS EN ARGENTINA}

Además de las citadas, varias regiones de Argentina evidenciaron rocas con contenidos de fósforo (en general bajos, hasta anomalías). Entre ellos se mencionan: la Precordillera de La Rioja, San Juan y Mendoza (areniscas con cemento fosfático); la subcuenca de Cacheuta en la provincia de Mendoza (lentes fosfáticos en lutitas carbonosas); las Sierras Septentrionales de Buenos Aires (anomalías de fósforo en dolomías de la Formación Villa Mónica) y la cuenca de Sierra Grande, en la provincia de Río Negro (fósforo en los niveles de areniscas ferríferas).

\section{Boratos en Argentina}

La Puna es el único ámbito geológico del país donde se encuentran depósitos de boratos, y uno de los pocos lugares del mundo que los poseen. En una superficie del orden de $100,000 \mathrm{~km}^{2}$, sus depósitos de boratos se distribuyen en una elongada faja de dirección NNE-SSO que abarca parte del oeste de las provincias de Jujuy, Salta y Catamarca. Los yacimientos más importantes, ubicados en la provincia de Jujuy (Puna Septentrional) y en la provincia de Salta (Puna Austral), producen variedades tincal, ulexita, hidroboracita y colemanita. Una pequeña proporción de su voluminosa producción se destina a la agricultura, donde el Boro representa un micronutriente de importancia.

Los depósitos de boratos en la Puna argentina corresponden a dos fajas litogenéticas: las facies evaporíticas en depósitos sinorogénicos terciarios, cuya explotación fue mencionada, y los depósitos evaporíticos de salares cuaternarios, donde se han reconocido boratos en los Salares Cauchari, Olaroz, Jama, Turi Lari, Hombre Muerto, Diablillos, Centenario, Ratones, Laguna Vilama, Laguna Guayatayoc y Salinas Grandes (Alonso y Viramonte, 1993; Alonso, 1999a, 1999b). Sus contenidos se exponen en el presente trabajo al considerar los recursos de potasio en salmueras de K-Li-B de la Puna.

\section{Ceolitas en Argentina}

La ceolita natural es uno de los minerales indicados para mejorar la capacidad productiva de los suelos, principalmente aquellos arenosos, debido a su aptitud para incrementar la retención hídrica (Torres Duggan et al., 2018). La presencia de ceolitas como componentes de rocas sedimentarias es conocida a partir de la importante obra de revisión de Teruggi y Andreis (1963) sobre ceolitas en rocas sedimentarias de Argentina.

En la provincia de La Rioja, a partir de estudios petrográficos de Prieri $(1982,2003)$ se reveló la presencia de ceolitas en la región de Patquía, confirmados y ampliados posteriormente en Carrizo et al. (2006). Según estos estudio, en el área las tobas ceolitizadas forman parte de la Formación Los Llanos de edad pliocena, depositada en un ambiente continental intermontano. Los aflora- 
mientos se presentan de modo discontinuo y se reconocen en Agua Blanca, El Médano, Represa El Mollar y la cantera El Toba-El Diaguita. En Agua Blanca el paquete de tobas vitrocristalinas de coloración blanquecino-verdosa muestra una potencia de 8 metros, aflorando un nivel continuo de toba ceolitizada de $4.5 \mathrm{~km}$ de extensión. En la actualidad las ceolitas de la provincia de la Rioja conforman parte de la oferta minera de este grupo mineral.

En el suroeste de la provincia de Mendoza, intercalados en tobas dacíticas terciarias, hay niveles de mordenita con cuarzo y de clinoptilolita (Bengochea et al., 1997; Canafoglia et al., 2008). Son objeto de exploración y de pruebas de aptitud para uso agrícola.

En la provincia de Chubut, los depósitos del Cretácico están vinculados a secuencias piroclásticas (tobas de caída) depositadas en cuencas lacustres del sector extraandino, depocentros de distribución errática cuyas secuencias se intercalan o están cubiertas con facies fluviales. Las facies piroclásticas del Grupo Chubut (Cretácico), denominadas como Formación Cerro Barcino o Formación Bajo Barreal, contienen ceolitas principalmente clinoptilolita/heulandita, mordenita y analcima, presentan gran distribución areal e importantes espesores; y se encuentran en sectores extraandinos con buen acceso (Donnari et al., 2017).

\section{Discusión}

De lo observado respecto a los ambientes geológicos con mejor y mayor desarrollo de minerales y rocas de uso agrícola, se destaca en Argentina la importancia de las unidades de la Cuenca Neuquina en la generación de estos depósitos (K, $\mathrm{S}, \mathrm{P}, \mathrm{Ca}, \mathrm{Mg}$ ).

Las rocas mesozoicas de la Cuenca Neuquina forman parte de una potente secuencia estratigráfica en la que alternan unidades detríticas, carbonáticas y evaporíticas de varios ambientes (Figura 10).

A partir del Jurásico se desarrolló una gran cubeta sedimentaria, con su eje orientado merid- ionalmente, resultado de la unión de una serie de pequeños depocentros formados durante el Triásico. El estilo de subsidencia de esta cuenca se mantuvo hasta el Cretácico superior (Legarreta y Uliana, 1999). A comienzos del Jurásico los depósitos eran de origen continental con interestratificación de rocas piroclásticas. Sólo en el norte de la cuenca se registran sedimentos marinos (areniscas y pelitas oscuras). A fines del Jurásico inferior y comienzos del Jurásico medio se desarrolló una gran cuenca marina y comenzó el denominado "ciclo Cuyano". La transgresión ingresó desde el norte y dio lugar a una cuenca de aguas relativamente profundas y fondos euxínicos, donde se acumularon las espesas sucesiones de pelitas grises y negras de la Formación Los Molles y Tres Esquinas (Legarreta y Uliana, 1999). Durante el Jurásico medio continuó el mismo ambiente depositacional con un importante incremento de las facies litorales - deltaicas y aluviales (Formación Lajas) y, hacia el final del Jurásico medio, sistemas depositacionales evaporíticos, carbonáticos y siliciclásticos controlados, en parte, por los cambios en el nivel de base.

La Formación Tábanos presenta una importante depositación de yeso, de 10 a 50 m de espesor, generado en la antigua zona de talud y cuenca. El Jurásico medio finaliza con un evento transgresivo representado por las arcillitas y areniscas de las formaciones Barda Negra y Lotena. Este pulso transgresivo permitió que en regiones anteriormente expuestas se instaurara un ambiente depositacional con escaso aporte clástico, favorable para la acumulación de depósitos carbonáticos (Legarreta y Uliana, 1999), como las calizas de la Formación La Manga (Jurásico superior). El posterior retiro de las aguas permitió que espesas capas de evaporitas (yeso de la Formación Auquilco) se depositaran en el interior de una cuenca profunda, pero de aguas marinas someras hipersalinas.

Durante el Jurásico superior tardío la cuenca vuelve a ser inundada y comienza el "ciclo Mendoza", generando un ambiente de cuenca profunda euxínica (Legarreta y Uliana, 1999), donde se depositó la Formación Vaca Muerta (Weaver, 1931). La Formación Vaca Muerta es una de las unidades 


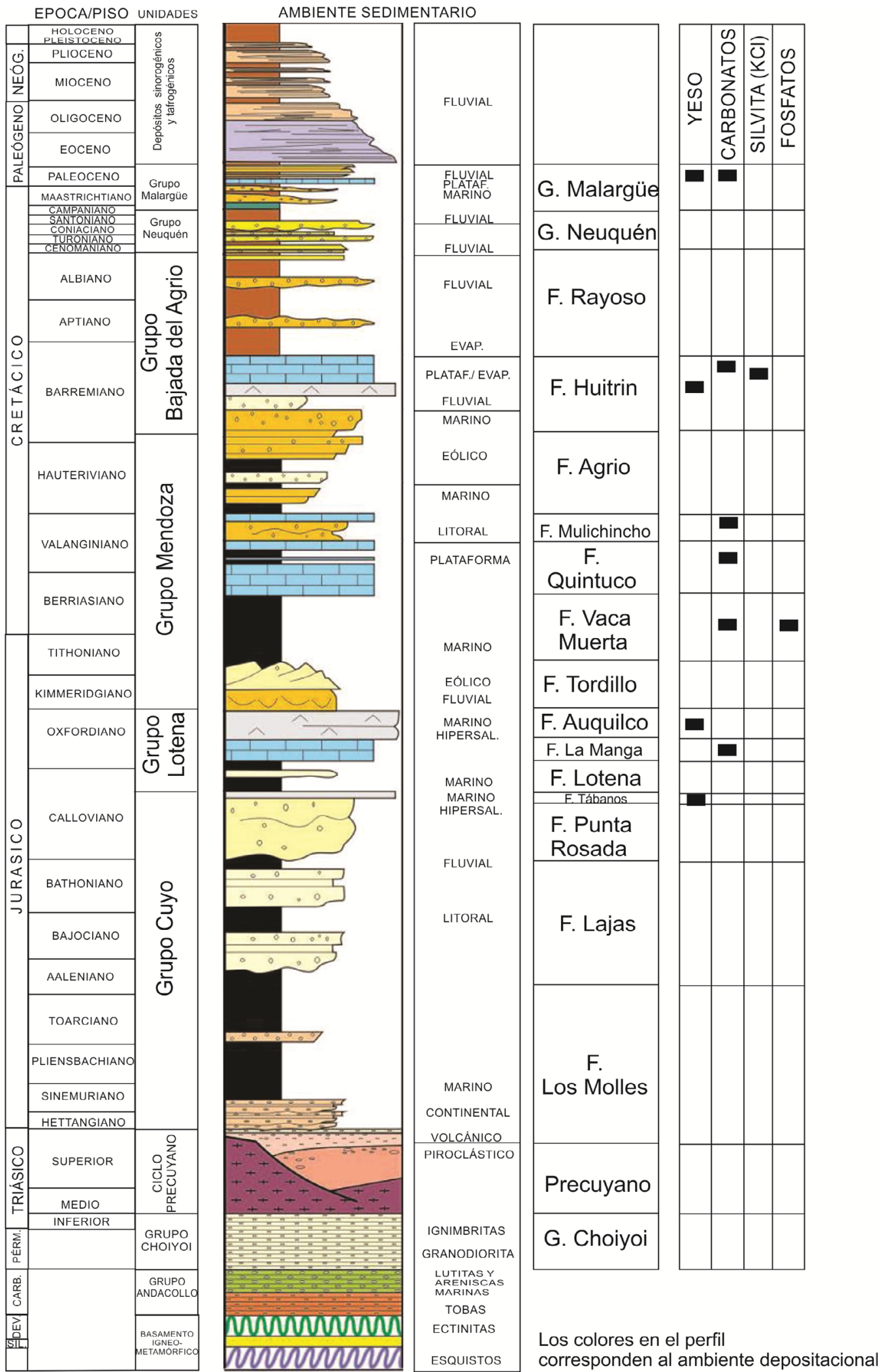

Figura 10 Potencial de recursos minerales para el agro (yeso, carbonatos, silvita, fosfatos) en la columna estratigráfica del Mesozoico de Cuenca Neuquina (columna litoestratigráfica y ambientes tomada de Arregui et al., 2011). 
litoestratigráficas con mayor extensión areal de la Cuenca Neuquina caracterizada por su uniformidad litológica dominada por pelitas negras y calizas micríticas (Weaver, 1931; Groeber, 1946; Leanza, 1973; Leanza et al., 1977). Representa las facies distales de una serie de sistemas carbonáticos y/o mixtos que se establecieron en la Cuenca Neuquina entre el Tithoniano temprano y el Valanginiano temprano (Legarreta y Uliana, 1991; Legarreta et al., 1993), donde también hay niveles fosfáticos. Se encuentra rodeada por una faja nerítica con depósitos carbonáticos de la Formación Quintuco y Formación Picún Leufú.

A comienzos del Cretácico inferior los sistemas depositacionales continuaban como durante el Jurásico superior, con la diferencia de un incremento en el desarrollo de facies clásticas, lo que produjo el achicamiento de la plataforma carbonática. El Cretácico inferior culminó con numerosos eventos de transgresión - regresión. En el Cretácico medio se depositaron las rocas de la Formación Huitrín y Formación Rayoso, caracterizadas por ser unidades netamente evaporíticas (con anhidrita, halita y silvita). En ellas se reconocen facies eólicas y de barreal (Miembro Troncoso inferior), facies evaporíticas (Miembro Troncoso superior), depósitos carbonáticos (caliza La Tosca) y por último facies fluviales y marinas restringidas.

El ciclo orogénico Patagonídico provocó el ascenso de la región cordillerana y plegó el relleno de la fosa del Agrio; se produjo la desvinculación de las cuencas mesozoicas del océano Pacífico y el mar comenzó a ingresar desde el este. En el Campaniano se produjo la inversión de la pendiente regional en la Cuenca Neuquina y Macizo de Somún Curá, que pasó a ser atlántica. En dicha región, luego de un prolongado periodo de continentalización donde tuvo lugar la depositación del Grupo Neuquén y Grupo Chubut al norte y sur del Macizo de Somún Curá, respectivamente, se reinstauró un ámbito sedimentario con definida influencia marina, representado por el Grupo Malargüe, de edad Campaniano tardío - Paleoceno. Así, la Cuenca Neuquina y el Macizo de Somún Curá fueron invadidos desde el Atlántico por dos brazos de mar que ingresaron por la cuenca del Colorado y el golfo de San Jorge (Uliana y Biddle, 1988).

La base del Grupo Malargüe está definida por la Formación Allen y equivalentes, como la Formación Loncoche y la Formación Huantraico, muy bien desarrollados en la Cuenca Neuquina. Los depósitos corresponden a facies de mares poco profundos, en algunos casos de circulación restringida, con una marcada tendencia -en varios sectores de la cuenca- a emerger e instaurar un ambiente evaporítico, como en el caso de los depósitos de Río Negro y Neuquén (Legarreta y Uliana, 1999). Esta unidad litoestratigráfica se apoya en discordancia erosiva sobre las sedimentitas del Grupo Neuquén (Herrero Ducloux, 1939); en su base presenta un nivel de areniscas medianas a gruesas de ambiente fluvial que transicionalmente pasan a arcillitas laminares verde olivas, de ambiente marino poco profundo, y culminan en niveles de yeso intercalados con rocas calcáreas producto del retiro del mar y la evaporación de cuerpos de agua aislados.

Posteriormente, durante el Maastrichtiano y Daniano, un nuevo episodio transgresivo inundó las depresiones epicontinentales que formaban la Cuenca Neuquina, ingresando a través de un brazo marino desde la cuenca del Colorado y continuando hacia el oeste en una faja litoral y una zona de bajadas. Esta disposición de ambientes se encuentra bien definida en el perfil oeste - este descrito por Legarreta y Uliana (1999), donde reconocen depósitos piroclástico-aluviales (Formación Pircala) seguidos por sedimentos arcillosos litorales, conectados a las rocas calcáreas organógenas (biostromas y biohermos) de la Formación Roca (correlacionable con la Formación Aguada Cecilio y parcialmente con la Formación Arroyo Barbudo, aflorantes en el este de Río Negro), unidad que se desarrolló en una rampa junto a acumulaciones supralitorales de carácter evaporítico. Más hacia el este se depositaron facies marinas de plataforma con buena circulación y en posición alejada de la costa (Formación Jagüel). 


\section{Conclusiones}

El panorama de la oferta y demanda de recursos minerales para el agro destaca la importancia del yeso, carbonatos cálcicos y magnesianos, y sales de potasio, por sus niveles de producción, consumo actual y futuro; así como por el potencial geológico del recurso. Por su parte, los boratos son requeridos en dosis muy bajas y determinadas ceolitas se encuentran en pruebas de aptitud.

Para el yeso su uso se prevé creciente y sin inconveniente de oferta mineral, tanto a partir de depósitos de la región central del país, como de la Cuenca Neuquina en las provincias de Mendoza y Neuquén.

La demanda de carbonatos se abastece fundamentalmente de dolomías de la región central del país (mármoles cálcico-magnesianos) y también de la Cuenca Neuquina, de donde además se exportan al vecino país Chile para el mismo uso.

Por otra parte, la presencia de una cuenca potásica con recursos del orden de $1 \mathrm{Gt} \mathrm{KCl}$ en la Cuenca Neuquina - con un proyecto minero ya desarrollado aunque aún no productivo-, sumado a la reciente puesta en valor del contenido de potasio de las salmueras exploradas y explotadas por litio en los salares de la Puna argentina, posiciona este elemento como unos de los principales y valiosos recursos no metalíferos de Argentina.

La necesidad de fósforo aún no logra ser cubierta con recursos minerales argentinos debido a que las numerosas manifestaciones -mayoritariamente rocas ligeramente fosfóricas, como las que se presentaron en este trabajo- no han evidenciado aún volúmenes que puedan constituir depósitos económicamente explotables.

De estos datos se concluye que los recursos necesarios para abastecer en gran medida las necesidades de nutrientes y enmiendas agrícolas son minerales y rocas que se encuentran presentes en el territorio argentino, con las condiciones, características geológicas y potencial que este trabajo expuso, y sobre las que pueden basarse actuales explotaciones y futuras exploraciones de sus depósitos, destacándose la Cuenca Neuquina entre todos los ambientes geológicos considerados.

\section{Agradecimientos}

Agradezco la dedicación del editor Dr. Carl Nelson además a los revisores de este trabajo, quienes con sus comentarios e indicaciones contribuyeron significativamente a la mejora del mismo.

\section{Referencias}

Advantage Lithium, 2018, Technical Report Lithium and Potassium Resources Cauchari Project, Jujuy Province, Argentina. Preparado por: F. Reidel, P. Ehren. Disponible en: https://www.orocobre.com/ wp/?mdocs-file $=4335$

Alonso, R., 1999a, Boratos terciarios de la Puna, Jujuy, Salta y Catamarca, en: E. Zappettini, (Ed.), Recursos Minerales de la República Argentina, Instituto de Geología y Recursos Minerales SEGEMAR.Buenos Aires, 1779-1826.

Alonso, R., 1999b, Los salares de la Puna y sus recursos evaporíticos, Jujuy, Salta y Catamarca, en: E. Zappettini, (Ed.), Recursos Minerales de la República Argentina, Instituto de Geología y Recursos Minerales SEGEMAR.Buenos Aires, 1907-1021.

Alonso, R., Viramonte, J., 1993. La cuestión genética de los boratos de la Puna. XII Congreso Geológico Argentino y II Congreso de Exploración de Hidrocarburos: Asociación Geológica Argentina, 5,187-194.

Amos, A., 1953, Estratigrafía de las formaciones paleozoicas de la Rinconada, pie oriental de la Sierra Chica de Zonda (San Juan): Revista de la Asociación Geológica Argentina 9, 1.

Andreis, R., Mazzoni, M., Spalletti, L., 1975, Estudio estratigráfico y paleoambiental de las sedimentitas terciarias entre pico Salamanca y Bahía Bustamante, provincia de Chubut, República Argentina: Revista de la Asociación Geológica Argentina, 30 (1),85-103.

Ardolino, A., 1980, Descripción geológica de la Hoja 47g, Garayalde, provincia de Chubut. Servicio Geológico Nacional, Buenos Aires. 
Ardolino, A., Panza, J., Yllanes, E., 1998, Hoja Geológica 4566-I, Garayalde, provincia de Chubut: Servicio Geológico-Minero Argentino, Boletín 264.

Arregui, C., Carbone, O, Sattler, F., 2011, El Grupo Lotena (Jurásico Medio-Tardío), en la Guenca Neuquina. Relatorio del XVIII Congreso Geológico Argentino, Neuquén, 91-98.

Armella, C., 1989, Estratigrafía de las Formaciones del límite Cámbrico-Ordovícico en la Precordillera Oriental: Universidad de Buenos Aires, Tesis de doctorado, 168 p.

Balod, M., 1999, Proyecto Potasio Río Colorado, Mendoza-Neuquén. En: E. Zappettini, (Ed.): Recursos Minerales de la República Argentina, Instituto de Geología y Recursos Minerales SEGEMAR.Buenos Aires, 1077-1081.

Bengochea, L., Mas, G., Maiza, P., Bengochea, J., 1997, Mordenite occurrence in the Mendoza province, Argentina, en: Zeolite '97. 5th International Conference on the occurrence, properties and utilization of natural zeolites, Ischia, Italia, 63-64.

Bengochea, J., Padula, V., 1993, Evaluación Geológica-Económica del proyecto Potasio Río Colorado, Mendoza, Argentina., En: V Congreso de Geología Económica, Asociación Geológica Argentina, 253-261.

Bordonaro, O., 1980, El Cámbrico en la quebrada de Zonda, Provincia de San Juan: Revista de la Asociación Geológica Argentina 35 (1), 26-40.

Bordonaro, O., 1999, Cámbrico y Ordovícico de la Precordillera y Bloque de San Rafael. En: R. Caminos (Ed.), Geología Argentina: Instituto de Geología y Recursos Minerales. SEGEMAR, 29 (8),189-204.

Borrello, A., 1962, Caliza La Laja (Cámbrico Medio de San Juan): Notas Comité Investigaciones Científicas de Buenos Aires 2, 3-8.

Bonalumi, A., Sfragulla, J., 2010, Carbonatos agroutilizables en la provincia de Córdoba. Ordenamiento Territorial, Contexto
Geológico y Tendencias Geoquímicas: Publicación del Departamento de Investigaciones Geológicas de la Secretaría de Minería de la provincia de Córdoba, Argentina.

Canafoglia, M., González M., Fernández, R., 2008, Reporte y caracterización de material zeolitizado en el sector suroeste de la provincia de Mendoza, en: XVII Congreso Geológico Argentino, Jujuy, Argentina, 1412. Carrizo, R., Donnari, E., Marcos, O., Prieri, A., 2006, Potencial Geológico-Minero de ceolitas sedimentarias en el distrito de Paganzo, Província de La Rioja, Argentina: Serie Contribuciones Técnicas Recursos Minerales. Servicio Geológico Minero Argentino, Buenos Aires, 29, 1-30.

Castro L., Scasso, R., Alonso, M., 1996, Caracterización y génesis de los fosfatos sedimentarios "Patagonienses" del valle del río Chubut, en: $3^{\circ}$ Reunión de Mineralogía y Metalogenia, INREMI, Universidad Nacional del Sur, Argentina, 87-90.

Castro L., Fazio, A., Scasso, R., Tourn, S., 2004, Geoquímica y diseños de distribución de tierras raras en los niveles fosfáticos dela Formación Gaiman (Mioceno inferior), Chubut, Argentina, en: $4^{\circ}$ Congreso Uruguayo de Geología: Sociedad Uruguaya de Geología, 12.

Castro, L., Scasso, R., Moya, M., 2009, Phosphate deposits in Argentina: State of the art. , en: COVAPHOS III, The third international conference on the valorization of phosphates and phosphorus compounds: Phosphate Fundamentals, Processes and Technologies in a Changing World. 5, 22-29.

Castro, L., Moya, M., Scasso, R., Fazio, A. Zelaya, A., 201 1, Geoquímica y distribución de tierras raras en los niveles fosfáticos del Ordovícico del noroeste argentino, en: XVIII Congreso Geológico Argentino (Neuquén), Asociación Geológica Argentina, 1068-1069.

Chmielowski J., Zandt, G., Haberland, C., 1999, The Central Andean AltiplanoPuna Magma Body: Geophysical Research 
Letters, 26 (6), 783-786. https://doi. org/10.1029/1999gl900078

Cruzate, G., Casas, R., 2014, Extracción y Balance de nutrientes en los suelos agrícolas de la Argentina, IAH, 2012. Relevamiento y Mapeo de la fertilidad en suelos agrícolas de la región pampeana Argentina, Proyecto Fertilizar-INTA, Instituto Nacional de Tecnología Agropecuaria, 1-8.

Dangavs, N., 2001, El depósito de yeso del arroyo Poronguitos, General Belgrano, Buenos Aires, en: VII Congreso Argentino de Geología Económica, Salta, Asociación Argentina de Geólogos Economistas, 73-77.

Dangavs, N., Blasi, A., 2002, Los depósitos de yeso intrasedimentarios del arroyo El Siasgo, partidos de Monte y General Paz, provincia de Buenos Aires: Revista de la Asociación Geológica Argentina, 57 (3), 315-327.

Donnari, E., Gozalvez, M., Ubaldón, M., Cozzi, G., Dal Molín, G., Castro Godoy, S., Marquetti, C., 2017, Investigación geológica y caracterización de depósitos de zeolitas de origen vulcano-sedimentarias en la provincia del Chubut: Recursos Minerales, 42, 1-20.

Fazio, A., Castro, L., Scasso, R., 2013, Geoquímica de tierras raras y fosfogénesis en un engolfamiento marino del Cretácico Tardío-Paleoceno de Patagonia, Provincia del Chubut, Argentina: Revista Mexicana de Ciencias Geológicas, 30(3), 582-600.

Fernández, R., 1983, Nuevos hallazgos de rocas fosfáticas marinas en la Cordillera Oriental de la provincia de Jujuy, República Argentina, en. Segundo Congreso Nacional de Geología Económica, San Juan, Argentina: Universidad Nacional de San Juan, 233-255.

Flores, M., 1979, Guenca de San Luis, en: Segundo Simposio de Geología Regional Argentina, Córdoba: Academia Nacional de Ciencias, 745-767.

Franchi, M., 1977, Descripción geológica de la Hoja 45g Monte Triste, provincia de Chubut. Servicio Geológico Nacional de Buenos Aires.
Gabriele, N., 1999 Guenca Potásica Huitriniana, Neuquén. En: Recursos Minerales de la República Argentina en: E. Zappettini, (Ed.), Recursos Minerales de la República Argentina, Instituto de Geología y Recursos Minerales SEGEMAR. Buenos Aires, 1083-1089.

Gabriele, N., 2016, Evapofacies del Miembro Troncoso Superior de la Formación Huitrín (Cretácico Inferior, Cuenca Neuquina, Argentina): paleoambientes, evolución y controles: Latin American Journal of Sedimentology and Basin Analysis, 23 (1), 35-69.

Gambaudo, S., Fontanetto, H., 2011, Diagnóstico de la acidez edáfica y su corrección, en: Simposio de Fertilidad, Rosario, Argentina: International Plant Nutrition Institute (IPNI).

García, F., Correndo, A., 2016, Cálculo de requerimientos nutricionales. Cereales, oleaginosas, industriales, forrajeras y hortalizas. International Plant Nutrition Institute (IPNI).

Gentili, C., Rimoldi, H., 1979, Mesopotamia, en Geología de la República Argentina, en: II Simposio Academia Nacional Ciencias, Córdoba, Argentina: ANC, 195-223,

Gómez Figueroa, J., Monardez, C., Balod, M., 2011, El Miembro Troncoso Superior de la Formación Huitrín (Cretácico Temprano), EN: XVIII Congreso Geológico Argentino: Asociación Geológica Argentina, 189-198.

Gozalvez, M., Herrmann, C., Zappettini, E., 2004, Minerales Industriales de la República Argentina: Servicio Geológico Minero Argentino, 39, 1666-3462.

Groeber, P., 1946, Observaciones geológicas a lo largo del meridiano 70. Hoja Chos Malal: Revista Sociedad Geológica Argentina 1 (3), 178-208.

Haller, M., Mendía, J., 1980, Las sedimentitas del ciclo Patagoniano en el litoral atlántico norpatagónico. Coloquio Ricardo Wichman, en: Congreso Geológico Argentino: Asociación Geológica Argentina, Buenos Aires, 8(3), 593-606. 
Herrero Ducloux, A., 1939, Reconocimiento geológico de la zona situada entre la vía férrea, el río Neuquén y el meridiano de Plaza Huincul: Informe inédito, Yacimientos Petrolíferos Fiscales Gerencia de Exploración. Buenos Aires, Argentina.

Herrmann, C., Torres Duggan, M., 2016, Fertilizantes y enmiendas de origen mineral: caracterización y uso en Argentina, en: F. Pereyra y M. Torres Duggan (Ed.), Suelos y Geología Argentina: Asociación Argentina de las Ciencias del Suelo y Asociación Geológica Argentina. Buenos Aires. 329-396 .

Herrmann, C., Frigerio, M., Giusiano, A., 2003, Potasio en Neuquén. Evaluación del Recurso en el Área de Exclusividad Provincial. Convenio SEGEMAR: Subsecretaría de Energía y Minería de la provincia del Neuquén, Argentina.

Houston, J., Butcher, A., Ehren, P., Evans, K., Godfrey, L., 2011, The Evaluation of Brine Prospects and the Requirement for Modifications to Filing Standards: Economic Geology, 106, 1225-1239. https://doi. org/10.2113/econgeo.106.7.1225

Igarzábal, A., 1999, Cuaternario de la Puna, en: R. Caminos (Ed.), Geología Argentina, Instituto de Geología y Recursos Minerales SEGEMAR, 683-687.

Igarzábal, A., Poppi, R., 1980, El salar de Hombre Muerto: Acta Geológica Lilloana, 15, 103-117.

Iñiguez, A., 1999, La cobertura sedimentaria de Tandilia. en: R. Caminos (Ed.), Geología Argentina, Instituto de Geología y Recursos Minerales SEGEMAR, 101-106 p.

Keller, M., Cañas, F., Lehnert, O., Vaccari, N., 1994, The Upper Cambrian and Lower Ordovician of the Precordillera (western Argentina): some stratigraphic reconsiderations: Newsletters on Stratigraphy 31,115-132. https://doi.org/10.1127/ nos/31/1994/115

Leanza, H., 1973, Estudio sobre los cambios faciales de los estratos limítrofes Jurásico-Cretácicos entre Loncopué y Picún Leufú, Provincia del
Neuquén, República Argentina. Revista de la Asociación Geológica Argentina 28: 97-132. Leanza, H., Hugo, C., Spiegelman, A., 1975, Manifestaciones fosfáticas en la Sierra de la Vaca Muerta y adyacencias, provincia del Neuquén, en: $2^{\circ}$ Congreso Iberoamericano de Geología Económica, Buenos Aires, Argentina, 461-483 p.

Leanza, H., Marchese, H., Riggi, J., 1977,Estratigrafia del Grupo Mendoza con especial referencia a la Formación Vaca Muerta entre los Paralelos $35^{\circ}$ y $40^{\circ}$ l.s. Guenca Neuquina-Mendocina: Revista de la Asociación Geológica Argentina 32 (3), 190-208.

Leanza, H., Spiegelman, A., Hugo, C., 1981,Manifestaciones fosfáticas de la Formación Patagonia: su génesis y relación con el vulcanismo piroclástico-silíceo: Revistas de la Asociación de mineralogía, petrología y sedimentología, 11 (3-4), 1-12.

Legarreta, L., Uliana, M.A., 1991, JurassicCretaceous Marine Oscillations and Geometry of Back Arc Basin, Central Argentina Andes, en: McDonald, D.I.M.(Ed.), Sea level changes at active plate margins: Process and product. International Association of Sedimentologists (IAS), Special Publication 12, 429-450.

Legarreta, L., Gulisano, C., Uliana, M., 1993, Las secuencias sedimentarias jurásico-cretácicas., en: Congreso Geológico Argentino No. 12 y Congreso de Hidrocarburos No. 2. , Mendoza, Argentina, 87-114.

Legarreta, L., Uliana, M., 1999, El Jurásico y Cretácico de la Cordillera Principal y la Cuenca Neuquina. Facies sedimentarias, en: R. Caminos (Ed.), Geología Argentina, Instituto de Geología y Recursos Minerales SEGEMAR, 399-432.

Lesta, P., Ferello, R., 1972, Región extraandina de Chubut y norte de Santa Cruz, en: Leanza, A. (ed.), Geología Regional Argentina: Academia Nacional de Ciencias, 601-654 p. Lithium X, 2016, NI 43-101 Technical Report on Salar Diablillos, Sal de los Angeles Project. 
Disponible en: http://www.lithium-x.com/ sal-de-los-angeles/.

Manning, D., 2018, Innovation in Resourcing Geological Materials as Crop Nutrients: Natural Resources Research, 27(2), 217-227.https://doi.org/10.1007/ s1 1053-017-9347-2

Mastandrea, O., Leanza, H., Hugo, G., Oblitas, C., 1982, Prospección de fosfatos sedimentarios en la República Argentina, en: Quinto Congreso Latinoamericano de Geología: Servicio Geológico Nacional, Subsecretaría de Minería, Buenos Aires, Argentina, 159-176.

Michelena, R., Irurtia, C., Vavruska, F., Mon, R., Pittaluga, A., 1989, Degradación de suelos del Norte de la Región Pampeana. Publicación Técnica $\mathrm{N}^{\circ}$ 6. INTA Instituto Nacional de Tecnología Agropecuaria. Buenos Aires.

Moya, M., Scasso, R, Castro, L., Fazio, A., 2012, Los fosfatos en el Ordovícico del Norte Argentino, en: XIII Reunión Argentina de Sedimentología, 145-167.

Nicolli, H., Suriano, J., Mendez, V., Gómez, M., 1982, Salmueras ricas en metales alcalinos del salar Hombre Muerto, Catamarca, Argentina, en: Quinto Congreso Latinoamericano de Geología: Servicio Geológico Nacional, Subsecretaría de Minería, Buenos Aires, Argentina, 187-204.

Olivero, E., Castro, L., Scasso, R., Zazio, A., Miretsky, P., 1998, Fosfatos marinos del Paleógeno de la Isla Grande de Tierra del Fuego: Revista de la Asociación Geológica Argentina, 53, (2), 239-246. Buenos Aires.

Poiré, D., 1993, Estratigrafía del Precámbrico de Olavarría, Sierras Bayas, Provincia de Buenos Aires, Argentina, en: XII Congreso Geológico Argentino y II Congreso de Exploración de Hidrocarburos: Asociación Geológica Argentina, 1-11.

Prieri, A., 1982, Estudio petrográfico de rocas tobáceas en el área de Patquía: Informe Inédito de la Delegación La Rioja, Servicio Minero Nacional. Argentina.
Prieri, A., 2003, Estudio petrográfico sobre tobas ceolíticas del área de Patquía: Informe Inédito, Servicio Geológico Minero Argentino.

Reig, O., 1957, Sobre la posición sistemática de "Zygolestes" con una reconsideración de la edad y correlación del "Mesopotamiense": Holmbergia 5, 12-13.

Romero, S., Schalamuk, I., 1992, Estudio geoeconómico de los depósitos yesíferos de Piedras Blancas. Departamento La Paz. Provincia de Entre Ríos: Informe inédito.

Ruiz Huidobro, O., 1960, El horizonte calcáreodolomítico en la provincia de Tucumán. Acta Geológica Lilloana, 3, 147-171.

Sainz Rozas, H., Eyherabide, M., Echeverría, H., Barbieri, P., Angelini, H., Larrea, G., Ferraris, G., Barraco, M., 2013, Cuál es el estado de la fertilidad de los suelos argentinos?, en: Conferencia International Plant Nutrition Institute IPNI y Fertilizar.

Salfity, J., Marquillas, R., 1999, La cuenca cretácico - terciaria del norte argentino. Instituto de Geología y Recursos Minerales: Geología Argentina 29 (19), 613-626.

Scasso, R., Castro, L., Lippai, H., Alonso, M., 1996, Significado estratigráfico y paleoambiental del conglomerado fosfático "Patagoniense" de Bryn Gwyn, Gaiman (Prov. del Chubut), en: $6^{\circ}$ Reunión de Sedimentología: Asociación Argentina de Sedimentología, 117-122.

Scasso, R., Bosch, P., Castro, L., 1998, Fosfogénesis, ambientes sedimentarios y cambios de nivel del mar: los fosfatos cenozoicos de Gaiman, provincia del Chubut, Argentina, en: X Congreso Latinoamericano de Geología y VI Congreso Nacional de Geología Económica, 195-207.

Servicio Geológico Minero Argentino (SEGEMAR), 1999, Normativa para las Cartas de Minerales Industriales, Rocas y Gemas de la República Argentina. INDUS-NOR-IGRM-001: Programa Nacional de Cartas Geológicas y Temáticas. Instituto de Geología y Recursos Minerales. Buenos Aires, Argentina.

Servicio Geológico Minero Argentino (SEGEMAR), 
2018, Recursos minerales en salmueras del noroeste argentino. Informe inédito. Buenos Aires, Argentina.

Sfragulla, J., Jerez, D., Bonalumi, A., 1999,Mármoles y otras rocas carbonáticas de Córdoba., en: E. Zappettini, (Ed.), Recursos Minerales de la República Argentina, Instituto de Geología y Recursos Minerales SEGEMAR.Buenos Aires, 271-295.

Teruggi, M., Andreis, R., 1963, Revisión de las zeolitas con especial referencia a su importancia sedimentológica: Revista de la Asociación Geológica Argentina 18, 1-2, 73-95.

Torres Duggan, M., Rodríguez, M., Lamelas, J., 2013, El azufre en los agro-ecosistemas: corrección de suelos y fertilización de cultivos., en: III Simposio Paraguayo de Manejo y Conservación de Suelos. Hoheneau-Itapua. Paraguay: Sociedad Paraguaya de Ciencia de Suelo.

Torres Duggan, M., Rodríguez, M., Castro, L., Leal, P., Cozzi, G., 2018, Mineralogía de una roca ceolítica y su aptitud para mejorar la retención hídrica de un suelo arenoso, en: XXI Congreso Argentino de la Ciencia del Suelo, Tucumán, Argentina: Asociación Argentina de la Ciencia del Suelo.

Tourn, S., Castro, L., Scasso, R., 2004, Composición y enriquecimiento de los fosfatos sedimentarios marinos en
Formaciones cretácicas, paleógenas y neógenas de Patagonia, Argentina, en: VII Congreso de Mineralogía y Metalogenia, Río Cuarto, Córdoba, Argentina, 285-290.

Turner, J., 1959, Estratigrafia del Cordón de Escaya y de la Sierra de Rinconada (Jujuy): Revista de la Asociación Geológica Argentina 13 (1-2), 15-44.

Turner, J., 1960, Estratigrafía del Nevado de Cachi y sector al oeste: Acta Geológica Lilloana, 3,191-226.

Uliana, M., Biddle, K., 1988, Mesozoic-Cenozoic paleogeographic and geodynamic evolution of southern South America: Revista Brasilera de Geociencias, 18 (2), 172-190. https://doi. org/10.25249/0375-7536.1988182172190

Uliana, M., Dellapé, D., 1981, Estratigrafía y evolución paleoambiental de la sucesión eoterciaria del Engolfamiento Neuquino (Patagonia septentrional), en: $8^{\circ}$ Congreso Geológico Argentino,Buenos Aires, 673-711.

Viramonte, J., Galliski, M., Araña Saavedra, V., Aparicio, A., Garcia Cacho, L., Martín Escorza, G. 1984, El finivolcanismo básico de la depresión de Arizaro, provincia de Salta, en: IX Congreso Geológico Argentino,Asociación Geológica Argentina, San Carlos de Bariloche, 234-251.

Weaver, C., 1931, Paleontology of the Jurassic and Cretaceous of West Central Argentine. University of Washington, Memoir 1, 594 p. 